\title{
Adjoint sensitivity studies of loop current and eddy shedding in the Gulf of Mexico
}

\author{
Ganesh Gopalakrishnan, ${ }^{1}$ Bruce D. Cornuelle, ${ }^{1}$ and Ibrahim Hoteit ${ }^{2}$ \\ Received 5 July 2012; revised 19 April 2013; accepted 13 May 2013; published 11 July 2013.
}

[1] Adjoint model sensitivity analyses were applied for the loop current (LC) and its eddy shedding in the Gulf of Mexico (GoM) using the MIT general circulation model (MITgcm). The circulation in the GoM is mainly driven by the energetic LC and subsequent LC eddy separation. In order to understand which ocean regions and features control the evolution of the LC, including anticyclonic warm-core eddy shedding in the GoM, forward and adjoint sensitivities with respect to previous model state and atmospheric forcing were computed using the MITgcm and its adjoint. Since the validity of the adjoint model sensitivities depends on the capability of the forward model to simulate the real LC system and the eddy shedding processes, a 5 year (2004-2008) forward model simulation was performed for the GoM using realistic atmospheric forcing, initial, and boundary conditions. This forward model simulation was compared to satellite measurements of sea-surface height (SSH) and sea-surface temperature (SST), and observed transport variability. Despite realistic mean state, standard deviations, and LC eddy shedding period, the simulated LC extension shows less variability and more regularity than the observations. However, the model is suitable for studying the LC system and can be utilized for examining the ocean influences leading to a simple, and hopefully generic LC eddy separation in the GoM. The adjoint sensitivities of the LC show influences from the Yucatan Channel (YC) flow and Loop Current Frontal Eddy (LCFE) on both LC extension and eddy separation, as suggested by earlier work. Some of the processes that control LC extension after eddy separation differ from those controlling eddy shedding, but include YC through-flow. The sensitivity remains stable for more than 30 days and moves generally upstream, entering the Caribbean Sea. The sensitivities of the LC for SST generally remain closer to the surface and move at speeds consistent with advection by the high-speed core of the current, while sensitivities to SSH generally extend to deeper layers and propagate more slowly. The adjoint sensitivity to relative vorticity deduced from the sensitivities to velocity fields suggests that advection of cyclonic (positive) relative vorticity anomalies from the YC or the LCFEs accelerate the LC eddy separation. Forward model perturbation experiments were performed to complement and check the adjoint sensitivity analysis as well as sampling the predictability and nonlinearity of the LC evolution. The model and its adjoint can be used in four-dimensional variational assimilation (4D-VAR) to produce dynamically consistent ocean state estimates for analysis and forecasts of the circulation of the GoM.

Citation: Gopalakrishnan, G., B. D. Cornuelle, and I. Hoteit (2013), Adjoint sensitivity studies of loop current and eddy shedding in the Gulf of Mexico, J. Geophys. Res. Oceans, 118, 3315-3335, doi:10.1002/jgrc.20240.

\footnotetext{
Companion to Gopalakrishnan et al. [2013] doi:10.1002/jgrc.20239.

${ }^{1}$ Department of Climate, Atmospheric Science and Physical Oceanography, Scripps Institution of Oceanography, La Jolla, San Diego, California, USA.

${ }^{2}$ Department of Earth Sciences and Engineering, King Abdullah University of Science and Technology, Kingdom of Saudi Arabia, Thuwal, Saud Arabia.

Corresponding author: G. Gopalakrishnan, Department of Climate, Atmospheric Science and Physical Oceanography, Scripps Institution of Oceanography, Nierenberg Hall, La Jolla, San Diego, CA 92093-0230, USA. (ggopalakrishnan@ucsd.edu)

\section{Introduction}

[2] The Gulf of Mexico (GoM) is a semienclosed basin which connects to the Caribbean Sea to the south through the Yucatan Channel (YC) and to the Atlantic Ocean to the east through the Straits of Florida. The YC, between Yuca$\tan$ Peninsula (west) and Cuba (east), is "V"-shaped and is $\sim 2000 \mathrm{~m}$ deep and $\sim 200 \mathrm{~km}$ wide at the surface, whereas the Straits of Florida, between Florida (north) and Cuba (south), is relatively narrower and shallower ( $\sim 900 \mathrm{~m}$ deep and $\sim 100 \mathrm{~km}$ wide at the surface). The Caribbean Currents which flows northward through the $\mathrm{YC}$, known as the "Yucatan Current," extends further northward into the 
GoM basin and loops southeastward forming the loop current (LC). The LC exits the GoM basin flowing eastward through the Straits of Florida, known as the "Florida Current," and eventually flows northward into the Atlantic Ocean joining the Gulf Stream. The strong western boundary flow comprised the Caribbean Current, the Yucatan Current, and the Florida Current together represent an important constituent of the North Atlantic subtropical gyre circulation [Sheinbaum et al., 2002].

[3] The LC is the major source of energy, variability, and momentum, driving most of the circulation within the GoM [Ohlmann et al., 2001]. The LC, with peak speed ranging 1.5-1.8 $\mathrm{m} \mathrm{s}^{-1}$ [Oey et al., 2005] carries warm and saline Yucatan waters into the GoM. The LC circulation in the GoM is highly variable, and the circulation features can be differentiated into three stages or "positions" depending on its northward extension into the GoM basin. A LC that flows in a retracted position, more or less directly from the $\mathrm{YC}$ to the Straits of Florida with a restricted northward penetration of $\sim 24^{\circ} \mathrm{N}$ into the eastern GoM is often referred to as "port-to-port" LC position [Schmitz, 2003]. The LC extends northward into the GoM basin before turning clockwise southeastward toward the Straits of Florida. A typical "averagely extended" LC position is marked by a northward extension of $\sim 26^{\circ} \mathrm{N}$, and a "fully extended" LC position is marked by a northward extension of $\sim 28^{\circ} \mathrm{N}$ [Leben, 2005]. As the LC extends northward into the GoM basin, progressing from the "port-to-port" position to "fully extended" position, it eventually forms a large, anticyclonic, warm-core, Loop Current Eddy (LCE) by completing its clockwise circulation. A newly formed LCE sometimes reattaches to the LC and detaches several times before its final separation, and this whole sequence of separation is defined as LCE shedding. Once the LCE completely separates and sheds into the GoM basin, the LC retracts back to the "port-to-port" position and these sequences of events are repeated at irregular intervals. These different stages of LC positions are schematically shown in Figure 1. This LCE have diameters of 200-400 $\mathrm{km}$, vertical extents of $\sim 1000 \mathrm{~m}$, and swirl speeds of $1.8-2$ $\mathrm{m} \mathrm{s}^{-1}$, and propagates predominantly westward at speeds of $2-5 \mathrm{~km} \mathrm{day}^{-1}$ and have an $e$-folding eddy decay timescale of $\sim 1$ year [e.g., Elliott, 1982; Forristall et al., 1992; Vukovich, 1995; Kirwan et al., 1984, see Oey et al., 2005 and references therein]. A detailed review of the LC circulation in and around the GoM can be found in Schmitz [2003].

[4] The mechanisms responsible for LCE shedding have been widely studied using theoretical and numerical models. A numerical modeling study by Hurlburt and Thompson [1980] reproduced the LC intrusion and eddy separation, while theoretical studies by Pichevin and Nof (1997) and Nof (2005) explained the LCE shedding phenomenon by a "momentum imbalance paradox." The LCE shedding interval mostly ranges from 6 to 11.5 months, with occasional longer shedding interval of 17 or even

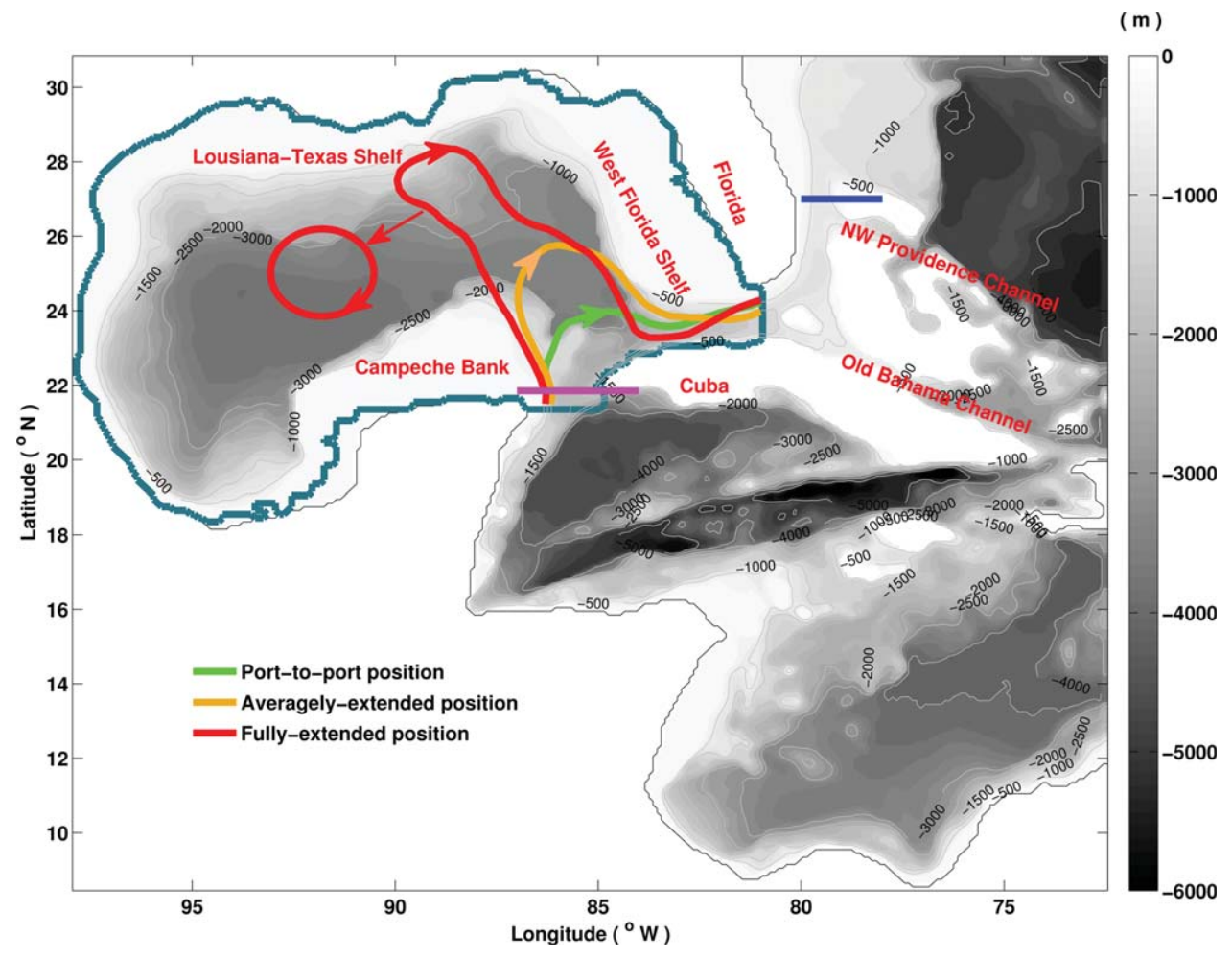

Figure 1. The MITgcm-IAS model topography. The shaded region denote water depth in meters. The thick magenta line across $21.85^{\circ} \mathrm{N}$ marks the $x-z$ section at $\mathrm{YC}$, and the thick blue line at $27^{\circ} \mathrm{N}$ marks the $x-z$ section at the Florida cable station. The spatial domain enclosed by the thick cyan line in the GoM represents the area over which LC indices were computed. The various stages of the LC extension: "port-toport" position (green), "averagely extended" position (golden), and "fully extended" position (red) based on Schmitz [2003] and Leben [2005], and a newly shed LCE (red) are shown schematically. 
18.5 months based on statistical and spectral analysis of satellite altimeter observations [Leben, 2005; Sturges and Leben, 2000] and modeling studies [Oey et al., 2003]. Occasional reattachment of the LCE before its final separation from the LC makes it difficult to clearly define, identify, and monitor an eddy shedding event in the GoM. A metric to identify LCE shedding and LC intrusion has been developed by Leben [2005] by tracking the $17 \mathrm{~cm}$ seasurface height ( $\mathrm{SSH})$ isoline based on satellite altimeter data. A detailed review of LC dynamics and GoM circulation with a numerical modeling perspective can be found in Oey et al. [2005], where the author discusses previous GoM modeling efforts and future challenges in modeling the complex LC dynamics and highly unpredictable LCE shedding.

[5] One of the popular hypotheses for the LC intrusion and LCE dynamics is the effect of the YC transport in preconditioning the LC extension, retraction and eddy shedding in the GoM. An early attempt to test this hypothesis using very deep current measurements in the YC was reported by Maul et al. [1985], but was unsuccessful in establishing a direct relationship between LC extension and deep Yucatan flows. Significant observational efforts involving direct measurements of through-flow between the Caribbean Sea and GoM were made through the CANEK program, which resulted in a remarkable data set on the YC flow structure. Sheinbaum et al. [2002] reported a net transport of $23.8 \mathrm{~Sv}\left(1 \mathrm{~Sv}=10^{6} \mathrm{~m}^{3} \mathrm{~S}^{-1}\right)$ across the YC based on nine months of CANEK data, lower than earlier estimates of Yucatan net transports. Ochoa et al. [2001] reported average net Yucatan transport of $24 \mathrm{~Sv}$ based on CANEK data along with a method using potential vorticity (PV) inversion, where a net inflow of $33 \mathrm{~Sv}$ and an outflow of $9 \mathrm{~Sv}$ were observed. The relationship between deep Yucatan flows and LC extension were further explored by Bunge et al. [2002] based on CANEK data, where a conceptual box model is used and found a high correlation between LC extension and deep Yucatan flows. Another study by Abascal et al. [2003] based on CANEK data reported that the variability of the flow through the YC is strongly influenced by the passage of mesoscale eddies with weak transport contributions, and also showed no significant correlation between the YC transport fluctuations and the local wind-stress forcing.

[6] The YC transport variability and the LC extension were also studied using a numerical model by Ezer et al. [2002, 2003], where the spatial extent of the LC was regressed against the meridional flow through the $\mathrm{YC}$ resulting in an estimated correlation between the LC extension area and the deep YC transport. These studies also established a direct relationship between the LC extension and deep Yucatan flow structure in accordance with the previous hypothesis.

[7] Another important finding from the CANEK observations is the effect of PV flux through the YC on the LC behavior in the GoM. Candela et al. [2002] reported that periods of negative (anticyclonic) cumulative PV influx through the YC results in LC extension into the GoM, whereas periods of positive (cyclonic) cumulative PV influx results in retraction of $\mathrm{LC}$ and sometimes triggered eddy separation. Conversely, a similar PV flux analysis through the YC based on numerical simulations was reported by Oey [2004], where influx of cyclonic vorticity flux anomaly (VFA) results in LC extension into the GoM, while influx of anticyclonic VFA may trigger retraction or eddy shedding. This uncertainty is one of the motivating factors for repeating this analysis using an adjoint approach.

[8] Counter-clockwise rotating cold-core current eddies of various sizes play a determinant role in the separation of warm-core LCE in the GoM [Schmitz, 2005]. This type of cyclonic cold-core eddy along the edge of the LC is referred to as a cyclonic loop current frontal eddy (LCFE). Earlier observational studies by Ichiye [1962], Cochrane [1972], Vukovich and Maul [1985], and Vukovich et al. [1979] based on in situ data and infrared images reported the occurrence of cold, cyclonic eddies with diameters of $80-120 \mathrm{~km}$, vertical extents of $\sim 1000 \mathrm{~m}$, and geostrophic velocity of $\sim 1 \mathrm{~m} \mathrm{~s}^{-1}$ along the eastern edge of the LC. A possible mechanism for the LCE separation is the southwestward propagation of a cyclonic LCFE from off the West Florida Shelf along the eastern edge of an extended LC, penetrating deeply to the west and leading to LCE detachment or separation. At times a pair of cyclonic eddies from the West Florida Shelf (east of the LC) and Campeche Bank (west of the LC) can constrict the "neck" of the LC, leading to a LCE detachment or separation, referred to as "necking-down" separation [Vukovich and Maul, 1985; Cochrane, 1972; Vukovich et al., 1979; Schmitz, 2005; Zavala-Hidalgo et al., 2003]. An extensive review on the role of cyclonic LCFE on the LCE separation processes is provided by Schmitz [2003, 2005]. Numerical modeling studies by Hurlburt [1986], Chérubin et al. [2006], and Le Hénaff et al. [2012] also explored the influence of cyclonic LCFE on LCE shedding sequences.

[9] The cyclonic LCFEs may sometimes grow and intensify by coalescence and move southeastward along the eastern edge of the LC following the West Florida Shelf [Vukovich, 1988]. These southeastward propagating LCFEs may slow down near the southern edge of the West Florida Shelf and form a slowly varying cyclonic circulation off the southern West Florida Shelf near the Dry Tortugas islands, called Tortugas eddies [Fratantoni et al., 1998], which eventually migrates into the Straits of Florida. Occurrences of cyclonic eddies on the west side of the LC near Campeche Bank were reported by Zavala-Hidalgo et al. [2003]. They were seen to move northwest along the Campeche Bank shelf-break and even northward toward the Mississippi shelf-break. The presence of cold-core cyclonic eddies in the northern, central, and western GoM and their dynamical interaction with the warm-core LCE were reported by Hamilton [1992] and Hamilton et al. [2002] using in situ observations.

[10] The LC and its extension, retraction and eddy shedding are complicated processes, making it difficult to monitor, predict, and forecast the circulation in the GoM. The prior work discussed above shows a multiplicity of potential influences on the LC evolution and eddy separation. Instead of simulating many forward model perturbation experiments, a single adjoint model simulation can evaluate all the potential influences, both in space and time. In the present study, we use the MIT general circulation model $(\mathrm{MITgcm})$ and its adjoint to trace dynamical linkages of the LC and eddy shedding in the GoM. An adjoint model is 
useful when the number of diagnostic quantities to be considered is smaller than the number of inputs that determine the output. Adjoint models are widely used in meteorology and oceanography with a variety of applications including sensitivity analysis, stability analysis, and variational data assimilation. A detailed overview of the concept of adjoint model and its various applications can be found in Errico [1997]. Many adjoint sensitivity studies have been reported in dynamical oceanography with a focus on ocean general circulation over a wide range of scales from regional coastal ocean circulation to mesoscale and gyre-scale circulation [e.g., Marotzke et al., 1999; Galanti and Tziperman, 2003; Hill et al., 2004; Li and Wunsch, 2004; Losch and Heimbach, 2007; Moore et al., 2009; Veneziani et al., 2009; Zhang et al. 2009, 2011]. These numerous adjoint model studies suggest the usability of the adjoint method to study the dynamical influences on the LC extension and eddy shedding in the GoM.

[11] The paper is organized as follows. Section 2 describes the model configuration, including model forcings, initial and open boundary conditions. The comparison of the forward model simulations with observations is discussed in section 3. Section 4 describes the adjoint sensitivity experiments and analyzes the adjoint model solutions. Forward sensitivity analysis using model perturbation experiments is discussed in section 5 , followed by discussion and conclusions in section 6 .

\section{MITgem Adjoint Model}

[12] The MITgcm [Marshall et al., 1997] integrates the primitive (Navier-Stokes) equations on a sphere under the Boussinesq approximation. The equations are written in $z$ coordinates and discretized using the centered second-order finite difference approximation in a staggered "Arakawa C-grid." The numerical code of the MITgcm is designed to enable computer generation of its adjoint model using the automatic differentiation tool Transformation of Algorithms in Fortran (TAF) [Giering and Kaminski, 1998; Heimbach et al., 2002]. It has been used in numerous state estimation and sensitivity studies at global and regional scales [e.g., Stammer et al., 2002; Fukumori et al., 2004; Menemenlis et al., 2005; Hoteit et al., 2009, 2010, 2012; Kohl et al., 2007; Mazloff et al., 2010].

\subsection{MITgcm-IAS Model}

[13] The MITgcm Intra-Americas Seas (MITgcm-IAS) model domain extends from $8.5^{\circ} \mathrm{N}$ to $31^{\circ} \mathrm{N}$ and from $98^{\circ} \mathrm{W}$ to $72.5^{\circ} \mathrm{W}$, covering the GoM, Caribbean Sea, and part of the Gulf Stream (Figure 1). The model is integrated on a $1 / 10^{\circ} \times 1 / 10^{\circ}$ spherical polar grid, with 40 vertical $z$ levels. The bathymetry is extracted from the 2 min gridded global topography (ETOPO-2). The vertical $z$ level spacing is $5 \mathrm{~m}$ at the surface, and the spacing gradually increases to $25 \mathrm{~m}$ at $160 \mathrm{~m}, 50 \mathrm{~m}$ at $360 \mathrm{~m}, 100 \mathrm{~m}$ at $775 \mathrm{~m}, 200 \mathrm{~m}$ at $1600 \mathrm{~m}, 300 \mathrm{~m}$ at $2600 \mathrm{~m}$, and $500 \mathrm{~m}$ at the maximum bottom depth of $6000 \mathrm{~m}$. In this configuration, the model is operated in hydrostatic mode with an implicit free surface. No-slip conditions are imposed at the lateral boundaries and a quadratic bottom friction with a drag coefficient of 0.002 is employed. The subgrid scale physics is approximated by a diffusive operator of second order in the vertical. Vertical diffusivity and viscosity are parameterized by Laplacian mixing with background values of $1 \times 10^{-6} \mathrm{~m}^{2} \mathrm{~s}^{-1}$ and 1 $\times 10^{-4} \mathrm{~m}^{2} \mathrm{~s}^{-1}$, respectively, and by the K-profile parameterization (KPP) in the surface mixed layer [Large et al., 1994]. In the horizontal, both the diffusive and viscous operators are of second order and fourth order with coefficients $1 \times 10^{2} \mathrm{~m}^{2} \mathrm{~s}^{-1}$ and $1 \times 10^{10} \mathrm{~m}^{4} \mathrm{~s}^{-1}$, respectively. These viscosity and diffusivity parameters were used for all forward model integrations including the model perturbation experiments. The adjoint model simulation for the sensitivity analysis used increased horizontal viscosity and diffusivity terms (second-order terms were increased by a factor of 10 and fourth-order terms were increased by a factor of 5), with the KPP mixing parameterization turned off. This suppressed the growth rates of small-scale flow instabilities, which otherwise produce large but nonlinear sensitivities in an eddy-permitting model [Hoteit et al., 2005; Kohl et al., 2007]. The larger scale sensitivities discussed later are not affected by this choice.

[14] The MITgcm-IAS model open boundaries (OB) are set at $30.85^{\circ} \mathrm{N}$ and $72.5^{\circ} \mathrm{W}$. The model $\mathrm{OB}$ conditions are extracted from the hybrid coordinate ocean model (HYCOM) global 1/12 ${ }^{\circ}$ analysis (http://hycom.org/dataserver/glb-analysis) using Navy Coupled Ocean Data Assimilation [Chassignet et al., 2007]. HYCOM estimates of temperature, salinity, and horizontal velocities (uvel: zonal component and vvel: meridional component) sampled at 15 day intervals were spatially interpolated onto the model grid and specified along the OB. The HYCOM horizontal velocities are prescribed at the grid points just outside the OB and the model state is relaxed to these values within a buffer zone of $1^{\circ}$ over time scales linearly varying from 1 day at the $\mathrm{OB}$ to 5 days at the inner edge of the buffer zone. The projected HYCOM normal velocity fields across the MITgcm-IAS OB have been adjusted to have zero net volume flux into the domain. The MITgcmIAS model forcings did not include tidal or atmospheric pressure forcing.

[15] The MITgcm-IAS model is forced with the National Centers for Environmental Prediction/National Center for Atmospheric Research Reanalysis-1 (NCEP/NCAR-R1) [Kalnay et al., 1996]. The model uses the bulk formulation [Large and Pond, 1981] for the computation of the atmospheric fluxes and the atmospheric forcing includes air temperature, specific humidity, zonal and meridional wind speed, precipitation, and short- and long-wave radiative fluxes. The NCEP/NCAR-R1 forcing fields were daily means having a spatial resolution of $2^{\circ} \times 2^{\circ}$ global grid. A monthly climatological run-off fluxes (freshwater) from the Estimating the Circulation and Climate of the Ocean (ECCO) global model [Stammer et al., 2002] were also prescribed in this model. To reduce any long-term effects of errors in precipitation and run-off fluxes, sea-surface salinity (SSS) was relaxed toward monthly climatology [Levitus et al., 1998] with a 30 day time scale. The SSS relaxation to monthly climatology was not used in the adjoint model simulation and forward model perturbation experiments.

[16] The MITgcm-IAS model was integrated over 5 year period from 2004 to 2008 using a variety of forcing products, including NCEP/NCAR-R1 winds and atmospheric fluxes as well as a combination of QuikSCAT SeaWinds (daily means with spatial resolution of $0.5^{\circ} \times 0.5^{\circ}$ global 
grid) and NCEP/NCAR-R1 atmospheric fluxes. The assimilated HYCOM $1 / 12^{\circ}$ global analysis estimates for temperature, salinity, and horizontal velocities (uvel and vvel) were used to initialize the simulations. The 5 year forward model simulations with two different wind products (NCEP/ NCAR-R1 and QuikSCAT) yielded similar results with respect to LC evolution matching the LCE shedding events within 0-3 months lag between the two experiments. In order to quantify the differences between the two wind products, the QuikSCAT and NCEP/NCAR-R1 daily sampled winds were also compared over the model domain for the 5 year simulation period (not shown). Although the mean and standard deviation of the zonal and meridional QuikSCAT winds were similar to those of NCEP/NCARR1 in the GoM basin, they differed in the IAS region, and QuikSCAT winds showed higher variability near the coasts than NCEP/NCAR-R1 winds. The standard deviation of the difference between QuikSCAT and NCEP/NCAR-R1 winds for the zonal and meridional components were at least $\sim 65 \%$ of the standard deviation of either over most of the model domain so the wind products were significantly different. The similar forward model solutions with two different wind products suggest that the local wind forcing is not dominant in modulating the LC dynamics in the GoM, but the adjoint model can better quantify these sensitivities. The forward model results discussed hereafter come from the model simulation using NCEP/NCAR-R1 winds and atmospheric fluxes.

\section{Model-Data Comparison}

[17] These comparisons use a forward model simulation with no data assimilation, but using assimilated HYCOM $1 / 12^{\circ}$ global analysis as initial and boundary conditions. Statistical comparison of model SSH from the 5 year simulation with gridded SSH from Archiving, Validation and Interpretation of Satellite Oceanographic (AVISO) data (http://www.aviso.oceanobs.com/duacs/), and of model sea-surface temperature (SST) with the optimally interpolated SST product derived from the Tropical Rainfall Measuring Mission's Microwave Imager (TMI) and the Advanced Microwave Scanning Radiometer for the Earth Observing System (AMSR-E) instruments produced by Remote Sensing Systems Inc. (http://www.remss.com/) are shown in Figure 2. The statistics of the observations were calculated over the model time range (2004-2008). The model SSH mean is similar to AVISO in the IAS and the eastern GoM, although the mean modeled LC is slightly weaker and thinner than AVISO. The eddies shed by the LC have a stronger effect in the model mean than in AVISO. The variability of the LC has the correct magnitude, but does not reach far enough north in the model and the eddies shedding from the LC are too strong in the west, due to the slow decay of modeled LCE in the western GoM. This increased model SSH variability in the western GoM can also be due to the westward propagating LCEs following a single pathway, whereas the observed LCEs propagate westward along several possible pathways [Vukovich, 2007]. The variability of the model SST is similar to the TMI-AMSRE data, especially the strong variability of the SST along the northern GoM continental shelf. In addition, the signature of the LC front is clear and its variability is approximately correct. The model SST mean is comparable to TMI-AMSRE mean but shows a positive bias of $\sim 1^{\circ} \mathrm{C}$ in the southern GoM possibly due to atmospheric flux variability and mixed layer physics.

[18] A set of LC indices [Leben, 2005] were also computed by tracking the $17 \mathrm{~cm}$ isoline of the SSH field obtained from 5 year model simulation and AVISO data over the model time range. The AVISO data were interpolated onto the model grid and used as the reference for this comparison. The SSH field from the model and AVISO data within the spatial domain highlighted by the thick cyan line in Figure 1 with their respective spatial mean removed were only considered for tracking the $17 \mathrm{~cm}$ isoline. Following the procedure reported by Leben (2005), the LC indices, defined by the maximum western longitude, maximum northern latitude, and length of the LC were computed for the model and AVISO SSH fields. The temporal mean, standard deviation, minimum, and maximum of these LC indices over 5 year period are summarized in Table 1. The time series of LC indices for the model and AVISO data are compared in Figure 3. The 5 year model simulations showed a LC system and eddy shedding at intervals varying from 6 to 9 months. The model also showed the occasional detachment and reattachment of LCE, in general agreement with observations and published results [Oey et al., 2003; Leben, 2005]. The modeled LC has an eastward and southward bias of $\sim 1^{\circ}$ with respect to LC frontal locations compared to AVISO SSH. This bias results because the modeled LC does not extend far enough westward or northward before eddy shedding. In general, the LCE shedding in the model is too regular compared to the observations. The maximum westward and northward LC extension before eddy separation reaches $\sim 89^{\circ} \mathrm{W}$ and $\sim 27^{\circ} \mathrm{N}$ in the model, whereas it reaches $\sim 90^{\circ} \mathrm{W}$ and $\sim 28^{\circ} \mathrm{N}$ in the AVISO data. After eddy shedding, the LC retracts to "port-to-port" position and the model shows the minimum LC extension reaching $\sim 86^{\circ} \mathrm{W}$ and $\sim 24^{\circ} \mathrm{N}$ compared to AVISO $\left(\sim 87^{\circ} \mathrm{W}\right.$ and $\left.\sim 25^{\circ} \mathrm{N}\right)$. Finally, the observed LC length is larger and more variable compared to the simulated LC. At times, the model simulates an LCE separation event at the same time as shown by AVISO data, but this may be coincidental. Overall, all the LC indices statistics for AVISO show larger variability than the model, indicating more LCE reattachment events, as is evident in the LC indices time series comparison (Figure 3). The model bias in the LC frontal positions and the quasiperiodicity in the LCE shedding are likely due to its relatively low resolution and high viscosity.

[19] The mean meridional velocity field across the YC $\left(x-z\right.$ vertical section at $21.85^{\circ} \mathrm{N}$, Figure 1$)$ was computed from the 5 year simulation and shown in Figure 4a. The modeled velocities are comparable with that of the CANEK observations [e.g., Sheinbaum et al., 2002; Ochoa et al., 2003; Candela et al., 2002] which showed a strong northward Yucatan Current in the upper western layers of the channel near the Yucatan peninsula, and a southward Cuban counter-current at the surface and deeper on the eastern part of the channel near Cuba. The volume transports across the YC and at the northern end of the Straits of Florida at the Florida cable station (Jupiter to Settlement Point, $x-z$ vertical section at $27^{\circ} \mathrm{N}$, Figure 1) were computed from the 5 year model simulation. The model mean 

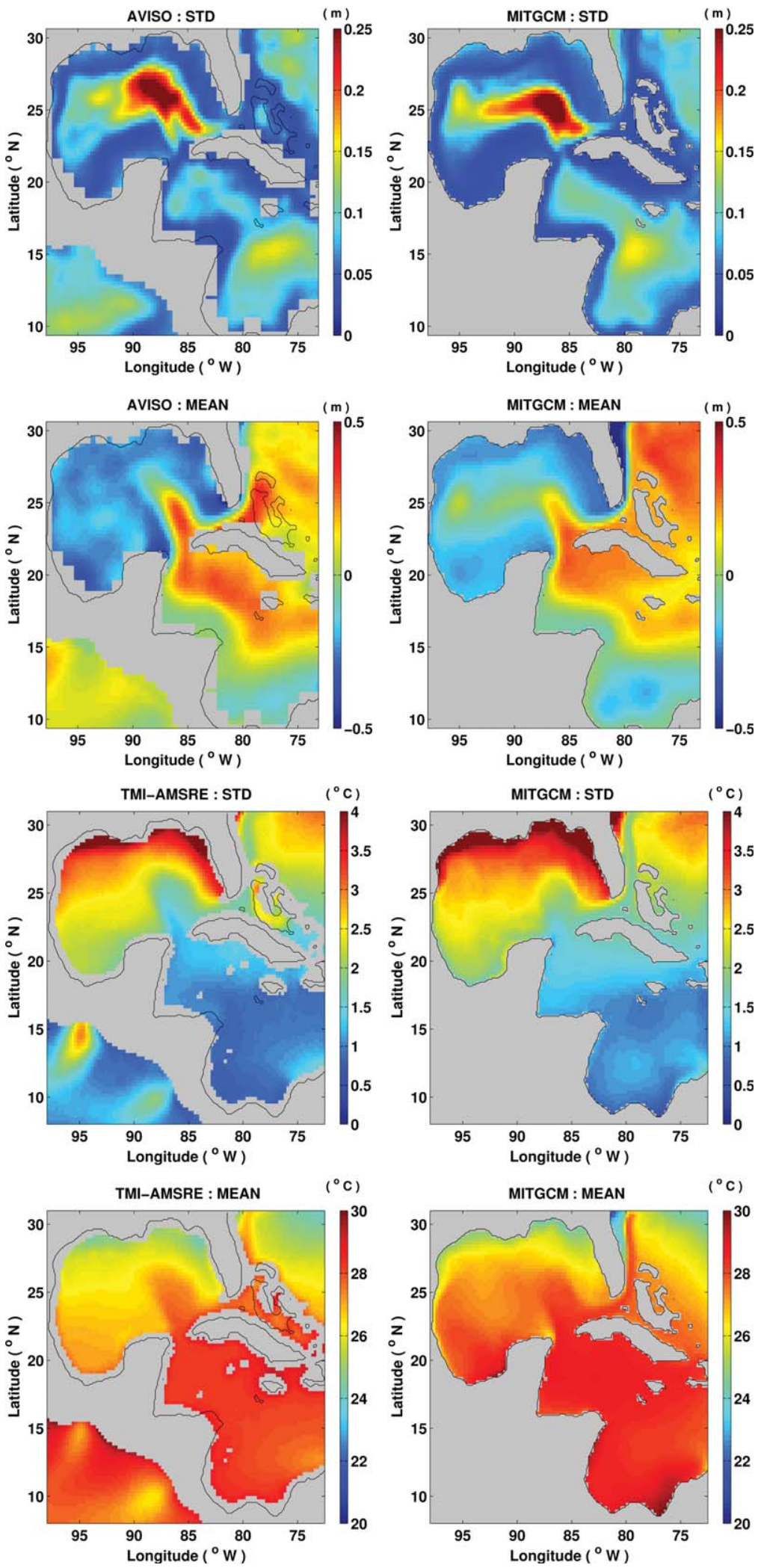

Figure 2. Comparison of SSH and SST statistics from AVISO and TMI-AMSRE observations (on left) and from the MITgcm-IAS model (on right) for the period of 2004-2008. The first row shows SSH standard deviation, the second row shows SSH mean, the third row shows SST standard deviation, and the fourth row shows SST mean. The left column has observations and the right column has model results. 
Table 1. Loop Current Indices

\begin{tabular}{llccc}
\hline Experiment & & $\begin{array}{c}\text { Maximum West } \\
\text { Longitude }\left({ }^{\circ} \mathrm{W}\right)\end{array}$ & $\begin{array}{c}\text { Maximum North } \\
\text { Latitude }\left({ }^{\circ} \mathrm{N}\right)\end{array}$ & Length $(\mathrm{km})$ \\
\hline AVISO & Mean & 88.17 & 26.69 & 1445.29 \\
& Standard deviation & 1.27 & 0.95 & 395.52 \\
& Minimum & 92.79 & 24.23 & 746.46 \\
MITgcm-IAS & Maximum & 86.28 & 28.64 & 2483.41 \\
& Mean & 87.09 & 25.44 & 1130.37 \\
& Standard deviation & 0.78 & 0.98 & 322.32 \\
& Minimum & 89.14 & 23.89 & 656.97 \\
& Maximum & 85.91 & 27.07 & 1841.78 \\
\hline
\end{tabular}

transport of 24.2 Sv at the YC (Figure 4b) is similar to the observed YC mean transport of $23.8 \mathrm{~Sv}$ [Sheinbaum et al., 2002]. The modeled transport at the Florida cable station was compared with the observed transport [Baringer and Larsen, 2001] for the same period and shown in Figure 4b. It differs from the observations in the early years of the simulation, but matches better in the later years, and the model mean transport $(27.1 \mathrm{~Sv})$ is smaller than the observed mean transport $(31.5 \mathrm{~Sv})$, as a consequence of the mismatch in the early years. The higher mean transport at the Florida cable station than at the $\mathrm{YC}$ is due to inflows through the Bahama passages and is consistent with findings showing that a sizable contribution to the Florida Current at the cable location may bypass the GoM and probably the Caribbean entirely [Sheinbaum et al., 2002; Hamilton et al., 2005; Badan et al., 2005]. Although the MITgcm-IAS model uses HYCOM solutions at its eastern and northern boundaries, its topography and interior flows differ from HYCOM, and these comparisons highlight the differences. As the flow exchange between the GoM basin and the northern Florida Strait is controlled by the topography of the Straits of Florida, higher resolution, tuned topography, and perhaps tidal forcing may be needed to match these details.

\section{Adjoint Sensitivity Experiments}

[20] The realism of this nonassimilated model simulation is meant to justify the suitability of the model and its adjoint to trace dynamical linkages in the ocean. Although the simulated LC eddy shedding events may be too regular, and not represent the wide range of phenomena in nature, the model provides a simplified test bed for tracing the influences on a typical event. In simple terms, an
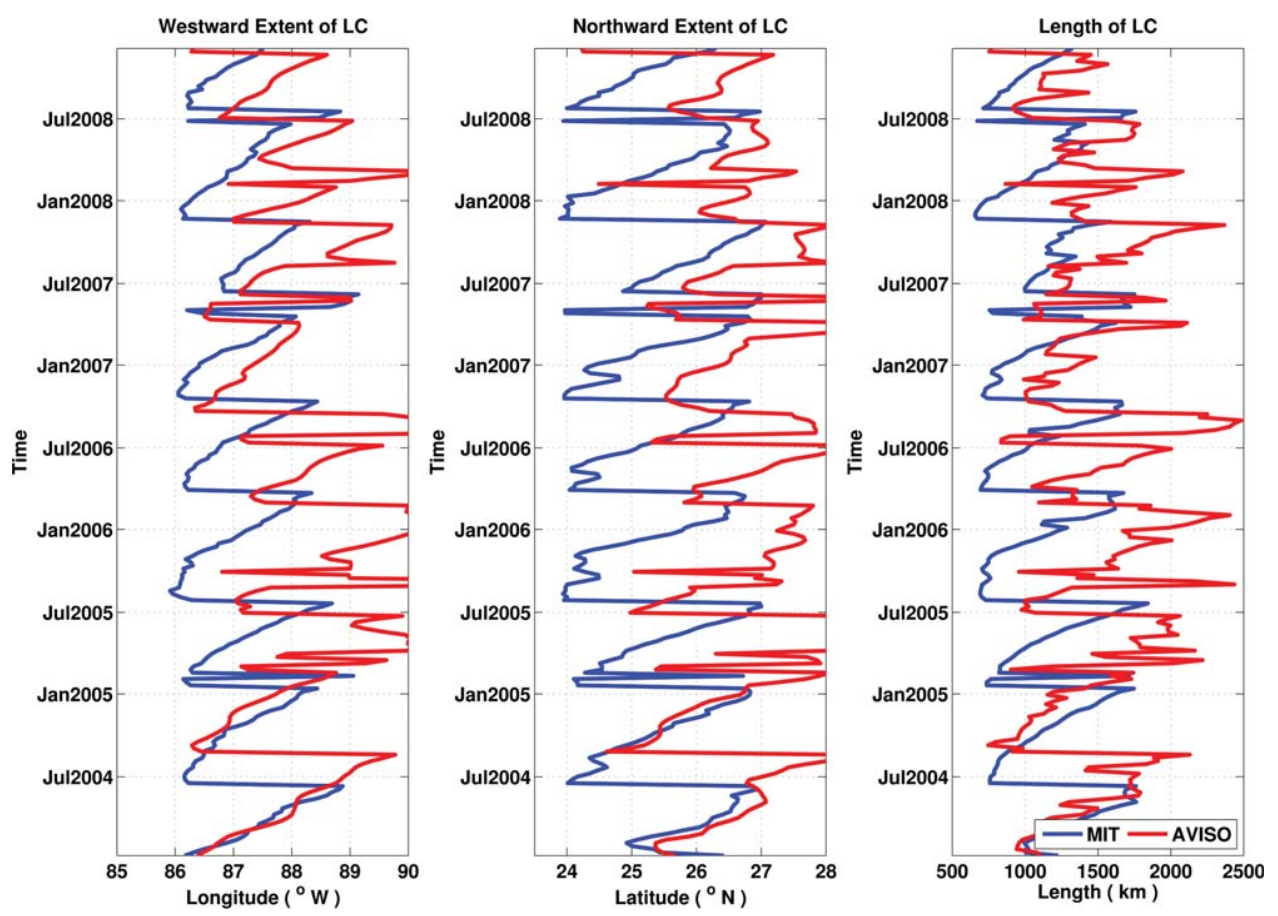

Figure 3. Time series of loop current (LC) indices for the model and AVISO data. The left plot shows maximum western longitude $\left({ }^{\circ} \mathrm{W}\right)$, the middle plot shows maximum northern latitude $\left({ }^{\circ} \mathrm{N}\right)$, and the right plot shows length of the LC in kilometers for both the model (blue curve) and AVISO (red curve) data for the period of 2004-2008. 

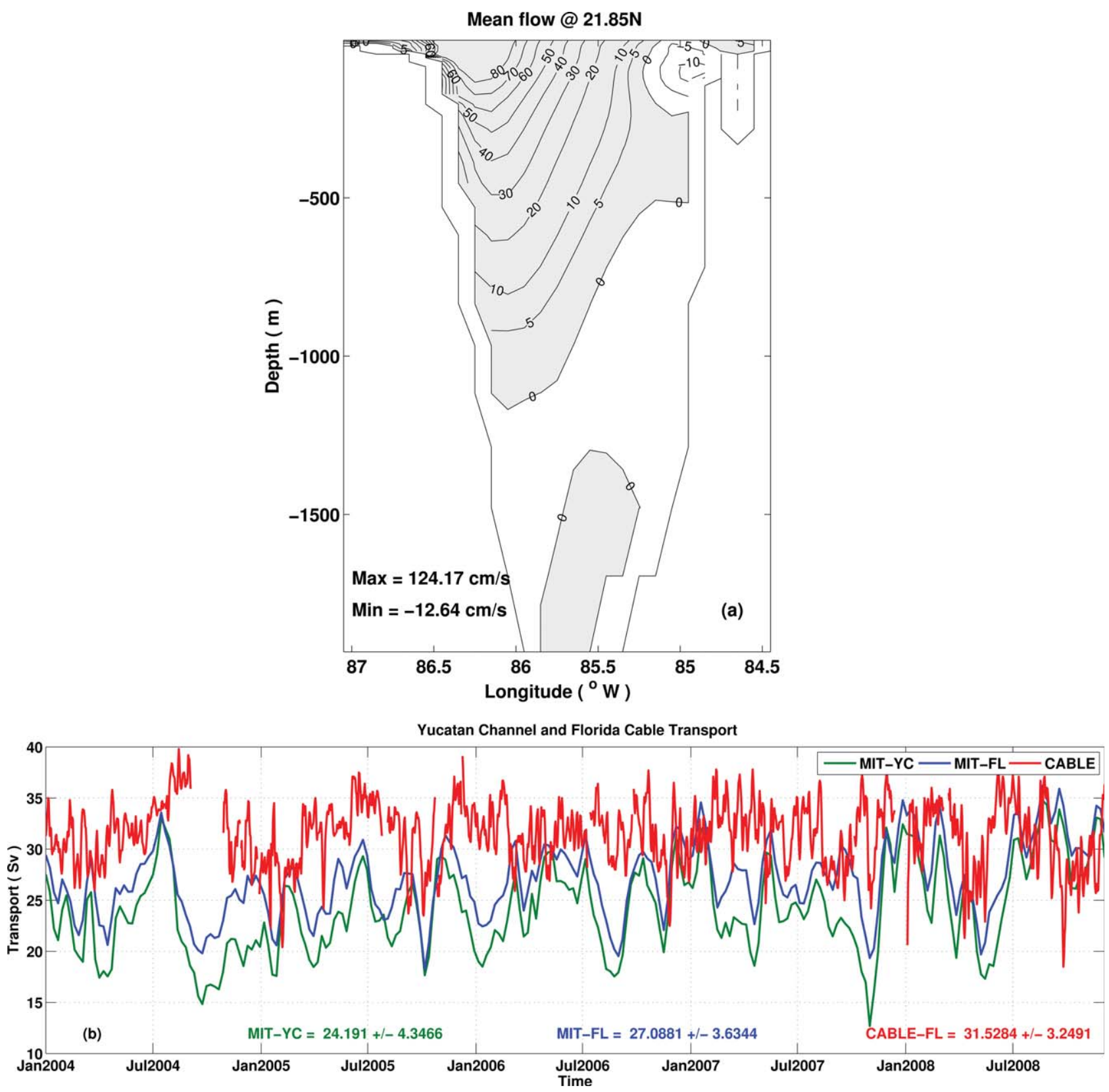

Figure 4. The top plot shows the mean flow across the $\mathrm{YC}$ at $21.85^{\circ} \mathrm{N}$ from the 5 year MITgcm-IAS model simulation with shaded region showing flow into the GoM. The bottom plot shows the time series of modeled transport across the YC and the Florida cable station (at $27^{\circ} \mathrm{N}$ ), and also the observed transport at the Florida cable station [Baringer and Larsen, 2001].

adjoint model computes the linearized gradient or "sensitivity" of a specified scalar measure of the model with respect to the model state at an earlier time and the forcing and boundary conditions, all of which are called the "control variables" of the system. The scalar measure of the system is usually called an "objective function" or "cost function." The adjoint sensitivity pattern is the rate of change of the cost function with respect to the control variables at an earlier time. The same field of sensitivities could be generated by running a set of perturbed forward model simulations over the same time period, changing one of the control variables for each run and calculating the change in the cost function at the end of each forward model integration. Following Errico [1997], a nonlinear model $\mathcal{M}$ can be defined as

$$
\mathbf{y}=\mathcal{M}(\mathbf{\Phi})
$$

where $\mathbf{y}$ is a vector representing a model output field and $\boldsymbol{\Phi}$ is a vector representing a model input field, also called a control vector. A differentiable scalar measure $\mathbf{J}$ of the model output can be defined as a sum of functions of the model output, often an average over a space-time region determined by the science question of interest

$$
\mathbf{J}=\mathbf{J}(\mathbf{y})
$$


and the perturbation, $\Delta \mathbf{J}$, of the cost function due to a change in the controls can be defined as

$$
\Delta \mathbf{J}=\mathbf{J}\left(\boldsymbol{\Phi}+\boldsymbol{\Phi}^{\prime}\right)-\mathbf{J}(\boldsymbol{\Phi})
$$

[21] A linear cost function $\mathbf{J}$ is a weighted sum of the model output fields and is simply differentiable with respect to the simultaneous model state, and the adjoint model computes the sensitivities of the cost function $\frac{\partial \mathbf{J}}{\partial \boldsymbol{\Phi}}$ to the control vector $\boldsymbol{\Phi}$ at earlier times $t$, which can be determined using the "chain rule"

$$
\frac{\partial \mathbf{J}}{\partial \boldsymbol{\Phi}_{i}}=\sum_{j} \frac{\partial \mathbf{y}_{j}}{\partial \mathbf{\Phi}_{i}} \frac{\partial \mathbf{J}}{\partial \mathbf{y}_{j}}
$$

where $i$ denotes the $i$ th component of the control input and $j$ denotes the $j$ th component of the model output. For linear cost functions, the $\left(\frac{\partial \mathbf{J}}{\partial \mathbf{y}_{j}}\right)$ term is the linear weight for $\mathbf{y}_{j}$ in the sum making up $\mathbf{J}$. The derivatives are taken around the time-evolving state of the forward model simulation determined by $\boldsymbol{\Phi}$, so the adjoint is a linearization around this state. The control vector, $\boldsymbol{\Phi}$, in these examples include the model inputs of atmospheric forcing, initial and boundary conditions, and the model state (sea-surface height, threedimensional temperature, salinity, and velocities).

[22] As mentioned above, sensitivities can also be obtained by perturbed forward model simulations, which is efficient when only a few perturbations are to be considered, and a forward simulation computes the resulting perturbation to the entire model state, not just a single scalar measure. An adjoint model is efficient when the number of features of interest is limited, so a single adjoint model simulation takes the place of many perturbed forward model simulations to quantify the perturbation-response relationship. Although the adjoint model is more practical than separate forward perturbation experiments for each model grid cell and variable at each time, it is only quantitatively correct for perturbation sizes and integration times within the system bounds of linearity. But, as with linear stability analysis, the linearized dependencies can often be useful even in the presence of nonlinearity.

[23] One of the goals of this study is to understand which ocean regions and circulation features control the evolution of the LC and eddy shedding in the GoM. To that end, adjoint model experiments were performed to examine the sensitivity of the northward extension of the LC and eddy shedding in the GoM. In addition, the adjoint model was used to identify circulation features that influence the transport at the northern end of the Straits of Florida by using model transport at $27^{\circ} \mathrm{N}$ between $80^{\circ}$ and $78^{\circ} \mathrm{W}$ as a cost function. The adjoint sensitivity experiments discussed in this study were performed for the year 2010 for 1-2 month periods including before, during, and after LCE (Eddy Franklin: simulated Eddy-F) separation at the end of May 2010. The MITgem-IAS forward model simulations were initialized using the HYCOM global analysis, adjusted slightly to approximate the observed eddy separation timing [Gopalakrishnan et al., 2013], and forced with climatological HYCOM open boundary conditions, NCEP/NCAR-R1 atmospheric forcing, and run-off fluxes. In the forward model simulation, the LCE (simulated Eddy-F) started detaching around 21 May and completely separated on 30 May, based on the position of the $17 \mathrm{~cm} \mathrm{SSH}$ isoline. In the AVISO observations, Eddy-F started detaching in late May 2010 and reattached and detached several times during the summer before complete separation from the LC in late September 2010. While the MITgcm-IAS forward model is too regular in its LC eddy shedding and does not simulate the large northward and westward extents of the LC that are seen in the AVISO observations (section 3), this model can serve as a laboratory for examining the factors that control a simple, and hopefully generic LC eddy separation. This adjoint model study can be considered as a first step for tracing the ocean influences leading to LC eddy separation in the GoM.

\subsection{Loop Current Sensitivity Analysis}

[24] For the LC sensitivity analysis, we consider two scalar cost functions as heuristic indicators of the LC growth and eddy separation: One for SSH $\left(\mathbf{J}_{\mathbf{S S H}}\right)$ and one for SST $\left(\mathbf{J}_{\text {SST }}\right)$. Both are averaged over a day (called "target day" in the following) and spatially averaged with uniform weight over identical $2^{\circ} \times 2^{\circ}$ target regions $\left(22.5^{\circ}-24.5^{\circ} \mathrm{N}\right.$, $87^{\circ}-85^{\circ} \mathrm{W}$ ), covering the area where LCE (simulated Eddy-F) separation took place in the 2010 MITgcm-IAS simulation. This is in the region where model and observation statistics agree well (Figure 2). Each cost function can be written as $\mathbf{J}=\frac{1}{\left(t_{2}-t_{1}\right) A} \int_{t_{1}}^{t_{2}} \int_{A} \boldsymbol{\Phi} \mathrm{d} A \mathrm{~d} t$, where $\boldsymbol{\Phi}$ can be either SSH or SST, $A$ is the area, and the time range is $t_{1}$ to $t_{2}$ ( 1 day in these examples). In the first experiment, the target day was 30 May 2010, when simulated Eddy-F had completely separated, as can be seen in Figure 5.

[25] The use of the $2^{\circ} \times 2^{\circ}$ box was a compromise between choosing only the small neck region linking the LC and eddy, which would give a more detailed idiosyncratic signal, and blurring the conclusions by averaging too widely. The location of the box is chosen to cover the neck of the LC, so that an increase in SSH in the box represents an extension of the LC (or the eddy) into the region, widening the neck, while a decrease in SSH in the box represents a larger separation and narrowing of the neck, eventually resulting in the LC eddy separation. A different separation location would require a different box location, again covering the neck between LC and eddy, although the simulated LC eddy separations were generally in the same region. After eddy separation, where the eddy has left the box, but the LC remains in the box, the box-averaged $\mathrm{SSH}$ still measures the extent of the LC, with LC extension increasing mean SSH in the box. If the box was smaller, and did not overlap the LC, an intrusion of the LC into the box would affect the SSH, but a retraction of the LC after eddy separation would not, so it would not be a linear measure. The rationale for the choice of average SST in the box is similar to that for SSH: the signature of the LC is warmer temperatures, and an increase in the temperature in the box represents a widening of the neck of the LC, while a decrease represents a narrowing of the neck. Uniform surface heating can change the temperature in the box without affecting the LC flow, so SST in the box is not a perfect indicator of the LC state, and in late summer the SST in the GoM may show little horizontal variation. To check the 

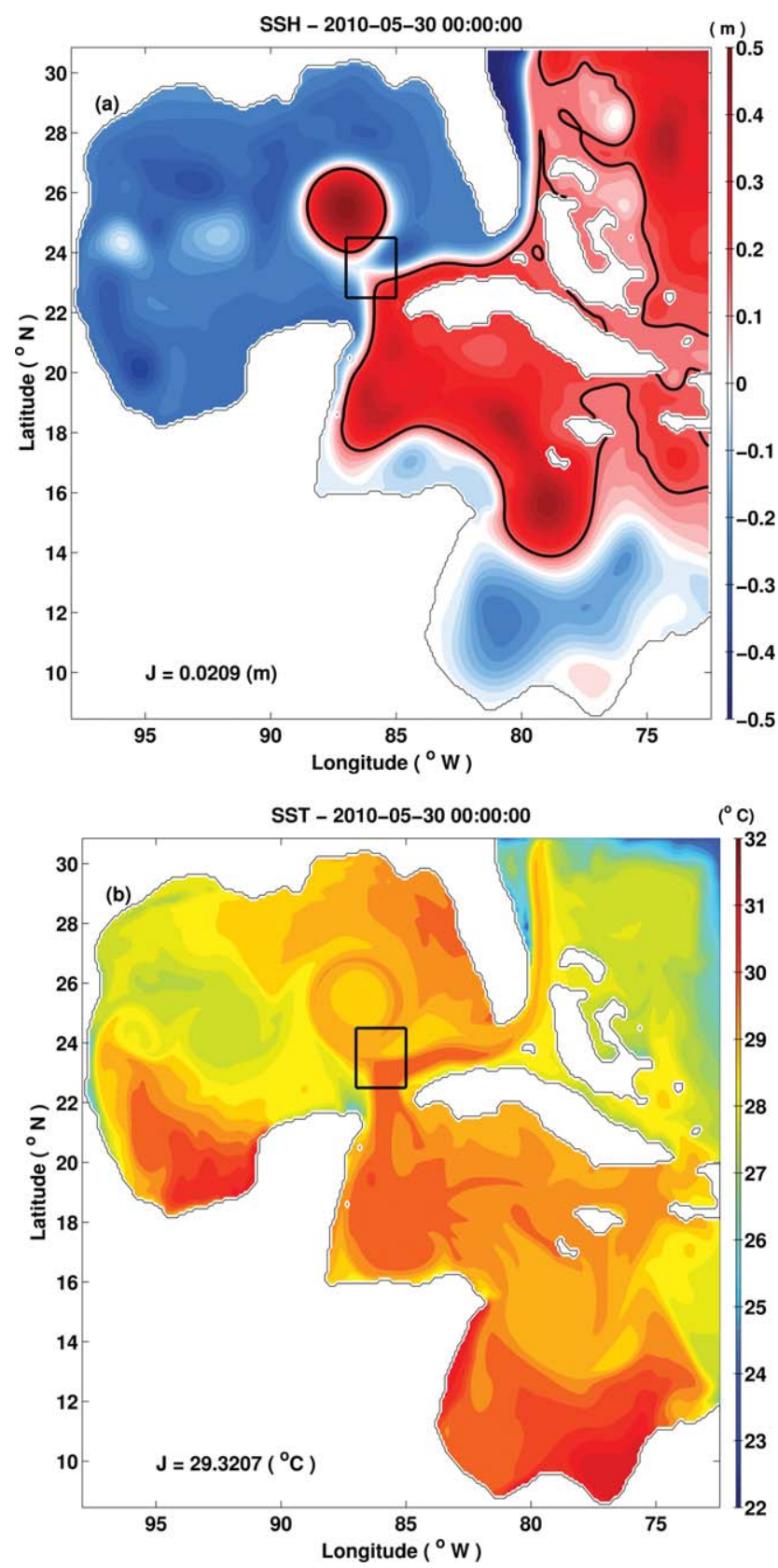

Figure 5. The MITgcm-IAS model SSH (top plot) and SST (bottom plot) on 30 May 2010, the "target day" for the LCE separation adjoint experiment.

cost functions, the mean SSH in the box and the difference between mean SST in the box and in the GoM basin (to remove large-scale seasonal heating) from the forward model simulation ending in eddy separation were studied with respect to time during eddy growth and separation (not shown). The indicators decrease monotonically as the eddy separates over the 30 day forward integration, and track the visual progress of separation, supporting the use of these indicators of LC eddy separation.

[26] To calculate the sensitivity for the "eddy separation" case, the adjoint model was integrated backward in time from the end of the target day to the start day: 1 May 2010 (30 days backward integration). The adjoint sensitiv- ity evolution for $\mathbf{J}_{\mathbf{S S H}}$ and $\mathbf{J}_{\mathbf{S S T}}$ to uvel and vvel surface current on selected days during the week preceding 30 May 2010 is shown in Figure 6. Positive sensitivity indicates increase in SSH or SST (meaning LC extension), and negative sensitivity indicates decrease in SSH or SST (meaning $\mathrm{LC}$ retraction or eddy separation) for a unit uvel or vvel perturbation at earlier times. The location of the $17 \mathrm{~cm} \mathrm{SSH}$ contour at the time of each snapshot is marked in green to guide the eye in locating the sensitivity in the context of the circulation of the forward simulation. The SSH sensitivities match up well to the contour, slightly more closely than the SST sensitivities. The horizontal sensitivity distributions for SSH and SST advect upstream in both the LC and the separating eddy as time progresses backwards. Relative vorticity or divergence are not model control variables, but the sensitivity can be approximately transformed by projecting the sensitivities to uvel and vvel onto differences of adjacent grid cells. Sensitivity to the vertical component of relative vorticity $\left(\frac{1}{f}\right)\left[\frac{\partial\left(\frac{\partial \mathrm{J}}{\partial \partial v e l}\right)}{\partial x}-\frac{\partial\left(\frac{\partial \mathrm{J}}{\partial \mathrm{zwel}}\right)}{\partial y}\right]$ and horizontal divergence $\left(\frac{1}{f}\right)\left[\frac{\partial\left(\frac{\partial \mathbf{J}}{\partial w v e l}\right)}{\partial x}+\frac{\partial\left(\frac{\partial \mathbf{J}}{\partial v e l}\right)}{\partial y}\right]$ can be estimated from the sensitivities to velocity fields by taking the indicated derivatives, so that a cyclonic horizontal shear in the sensitivity corresponds to a sensitivity to cyclonic (positive) relative vorticity. These derivatives of adjoint sensitivities with respect to vertical component of relative vorticity were computed for $\mathbf{J}_{\mathbf{S S H}}$ and $\mathbf{J}_{\mathbf{S S T}}$ and are shown for the surface level on selected days during the week preceding 30 May 2010 in Figure 7. In the MITgcm-IAS simulation of Eddy-F separation, the presence of a cyclonic LCFE extending from the West Florida Shelf to the separating neck of the LC is evident in the model SSH shown in Figure 5 and the location can be inferred in Figure 6 from the $17 \mathrm{~cm} \mathrm{SSH}$ contour. Figure 7 shows negative (promoting separation) sensitivity to cyclonic relative vorticity on the west and northwest edge of the LCFE. The sensitivity to relative vorticity in the cyclonic eddy is stronger for SSH than for SST and the gradients are larger for uvel than for vvel at the end of the first week of backward integration. Since a cyclonic eddy has positive relative vorticity, an increase in the strength of the eddy promotes separation, in line with prior descriptions of the roles of cyclonic LCFE or "meanders" [Cochrane, 1972] on the LC eddy separation.

[27] The surface current sensitivities extend smoothly upstream through the $\mathrm{YC}$, stronger for SSH and for meridional current than for SST and zonal current. There is a positive effect (greater LC extension, less separation) from a stronger northward flow in the west, near the Campeche Bank and from a southward flow in the east (near Cuba). This again can be seen as negative sensitivity to relative vorticity (Figure 7), so a cyclonic vorticity anomaly in the YC will promote separation a few days later. This agrees with prior results suggesting the influence of cyclonic (positive) relative vorticity anomalies advected through the $\mathrm{YC}$ triggering LC retraction or eddy separation [Candela et al., 2002]. The large horizontal scale of the sensitivity to meridional current makes it clear that large-scale horizontal shear with relatively small vorticity can still have an important effect on the LC system. 

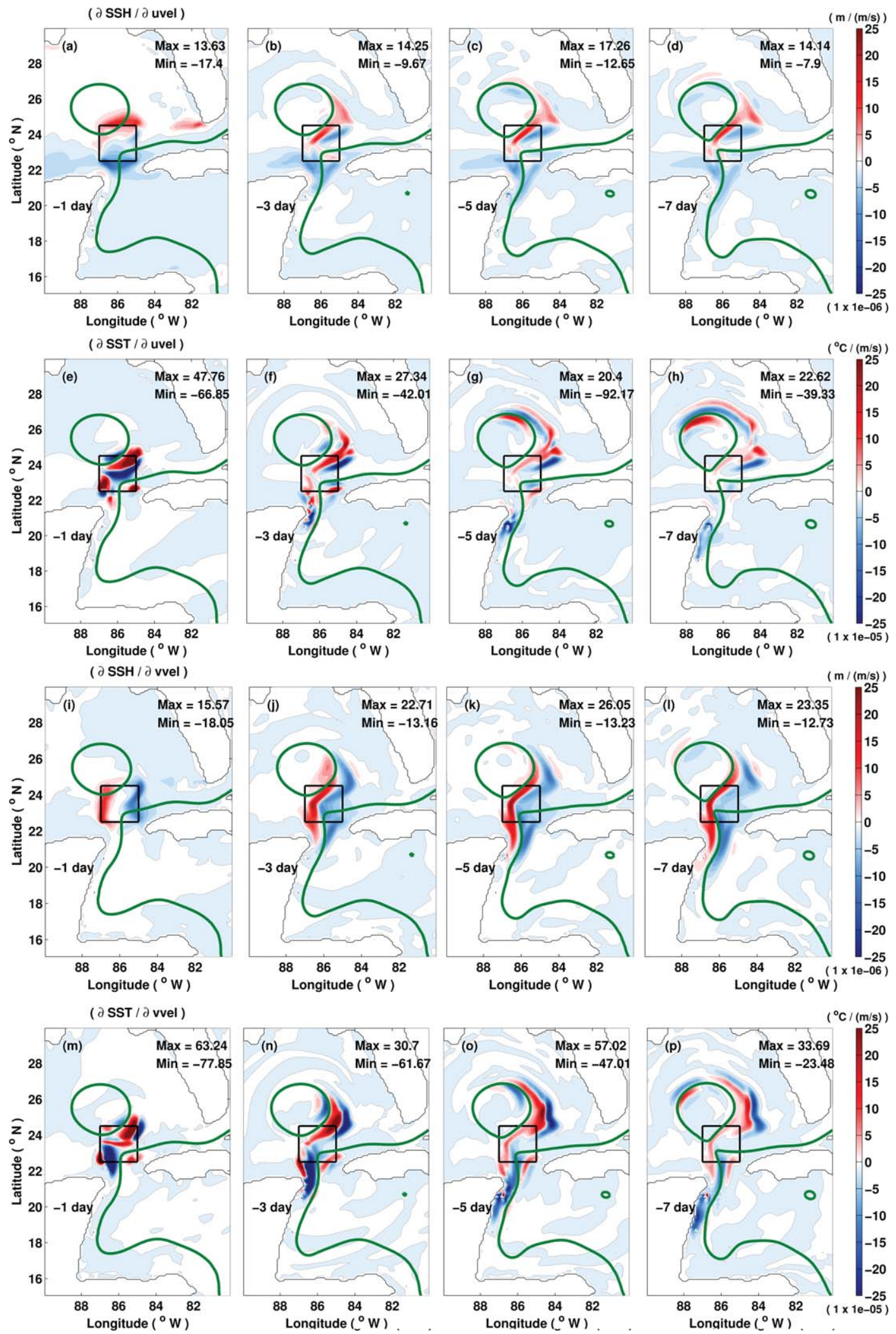

Figure 6. Evolution of the adjoint sensitivity, backward in time (from left to right) for $\mathbf{J}=\mathrm{SSH}$ and $\mathbf{J}=$ SST with respect to uvel and vvel at the surface for the first week of backward integration. The top two plots (a-d) shows $\frac{\partial \mathrm{SSH}}{\partial u v e l}$ and (e-h) shows $\frac{\partial \mathrm{SST}}{\partial u v e l}$. The bottom two plots are the same as the top two plots, but for vvel. The black box near the YC marks the spatial domain over which $\mathbf{J}$ is computed, and the gray lines mark zero contours. The green contour marks the $17 \mathrm{~cm} \mathrm{SSH}$ isoline indicating the LC position at the time of the snapshot. 

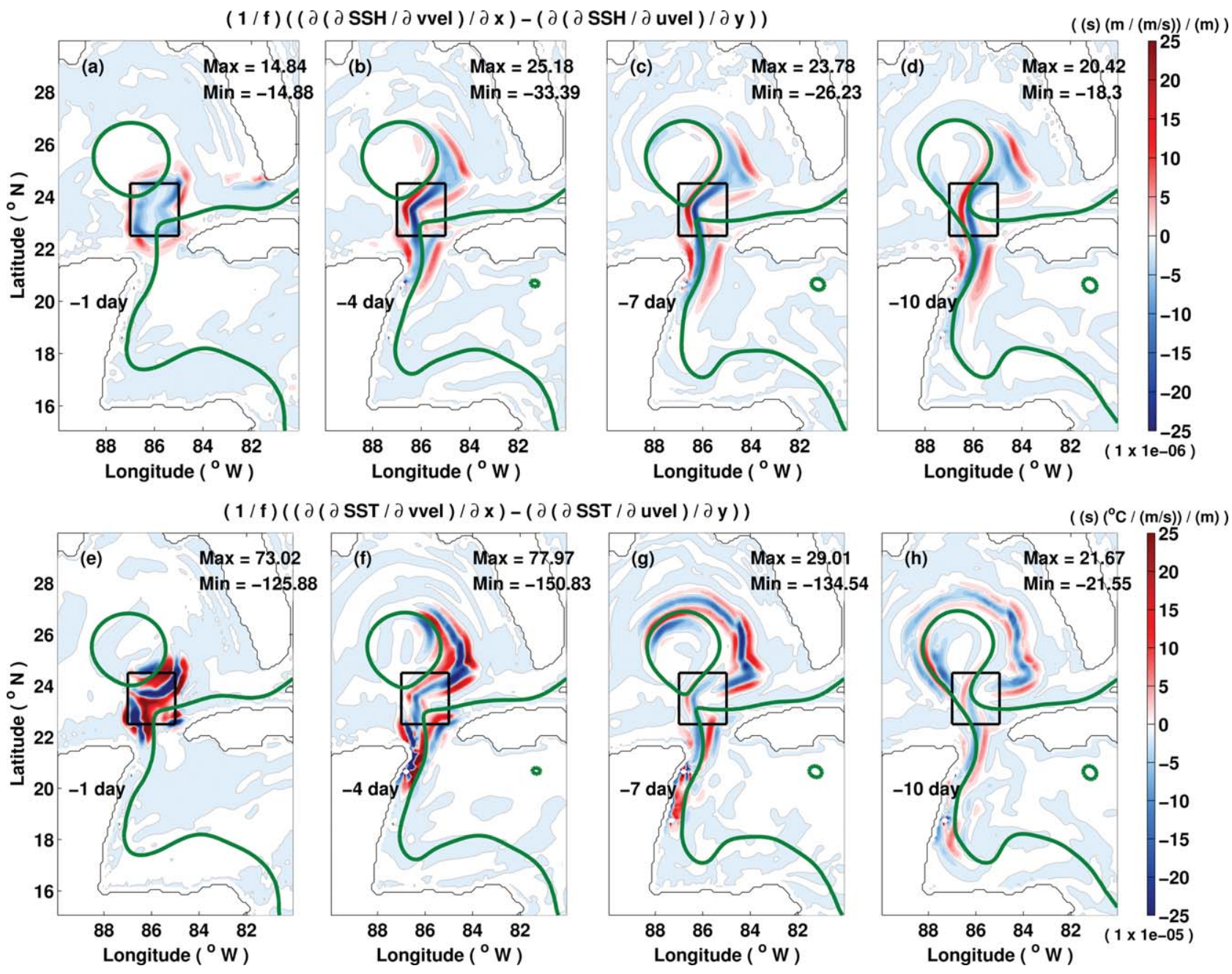

Figure 7. Evolution of the adjoint sensitivity, backward in time (from left to right) for $\mathbf{J}=\mathrm{SSH}$ and $\mathbf{J}=$ SST with respect to relative vorticity: $\left(\frac{1}{f}\right)\left[\frac{\partial\left(\frac{\partial J}{\partial v e l}\right)}{\partial x}-\frac{\partial\left(\frac{\partial J}{\partial v e l}\right)}{\partial y}\right]$ at the surface for the first week of backward integration. The top plots (a-d) are for $\mathbf{J}=$ SSH and the bottom plots (e-h) are for $\mathbf{J}=\mathrm{SST}$. The black box near the YC indicates the spatial domain over which $\mathbf{J}$ is computed, and the gray lines mark zero contours. The green contour marks the $17 \mathrm{~cm} \mathrm{SSH}$ isoline indicating the LC position at the time of the snapshot.

[28] Because of the relatively weak sensitivity of SST and SSH to uvel in the YC, and to study the dependence of the LC dynamics on the meridional YC flow structure, the following discussion focuses on the influence of the meridional flow ( $v v e l)$ on the LC extension and eddy separation, showing only sensitivity of $\mathbf{J}$ to $\mathrm{vvel}$.

[29] The SSH sensitivity to vvel in a section across the $\mathrm{YC}$ at $21.85^{\circ} \mathrm{N}$ after the first day of the adjoint backward integration (Figure 8a) shows a primarily barotropic sensitivity, a consequence of barotropic mass balance in the GoM where increased flow through the $\mathrm{YC}$ will tend to increase the SSH in the GoM, including the target region. The sensitivities have been divided by the grid cell size to remove the effects of varying depth level spacing. During 3-7 days of the adjoint backward integration (Figures $8 b-$ $8 d$ ), the vertical structure of the near-surface sensitivities of SSH to vvel correspond to the velocity signature of a positive SSH anomaly roughly centered at the longitude of the
$17 \mathrm{~cm} \mathrm{SSH} \mathrm{contour} \mathrm{at} \mathrm{the} \mathrm{YC}$ (marked in green at the $\mathrm{YC}$ in Figure 6). After 3 days of backward integration the sensitivity is strongest near the surface, corresponding to a broad vertical baroclinic mode spectrum. Although the strong currents mean that linear wave theory is not accurate, this suggests the importance of advection, since higher baroclinic modes propagate slowly and could not reach the target area in 3 days. Stronger and deeper lobes of opposite sign gradually appear at longer time lags, resembling lower baroclinic modes. The sensitivities of SST to vvel (Figures $8 \mathrm{e}-8 \mathrm{~h}$ ) involve baroclinic modes, so even with nonlinearity there is little barotropic sensitivity after 1 day of the adjoint backward integration, and only the region of highest velocity has an effect on the target region after a day (Figure 8e). After 3 days, the sensitivities are still dominated by a positive lobe where the current is fast enough to advect temperature from the $\mathrm{YC}$ to the target region in 3 days. For longer time lags, the SST sensitivity remains strongest within 

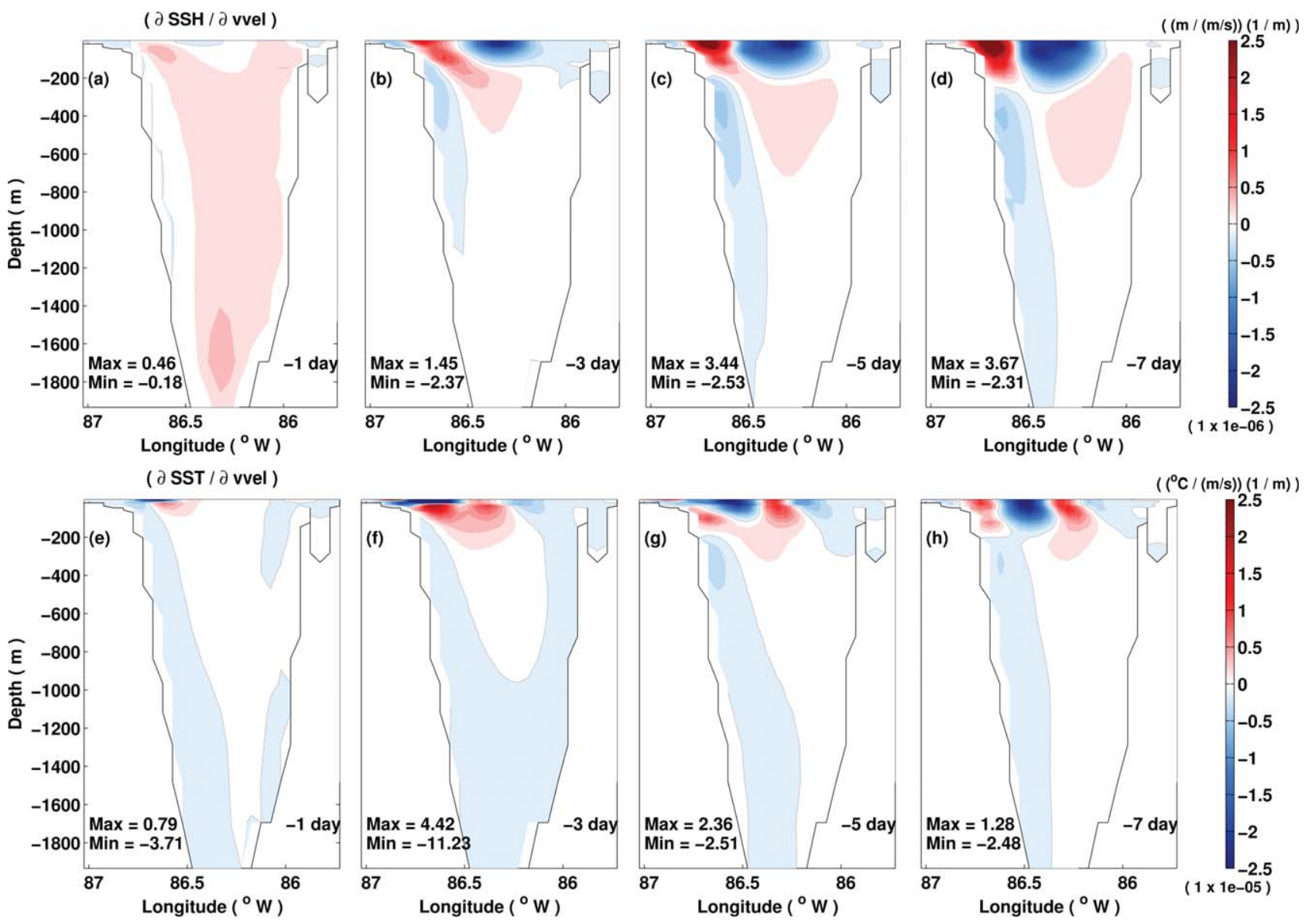

Figure 8. Evolution of the adjoint sensitivity per unit depth, backward in time (from left to right) for $\mathbf{J}=\mathrm{SSH}$ and $\mathbf{J}=\mathrm{SST}$ with respect to $v v e l$ at the $\mathrm{YC}$ at $21.85^{\circ} \mathrm{N}$ for the first week of backward integration. The top plots $(\mathrm{a}-\mathrm{d})$ shows $\frac{\partial \mathrm{SSH}}{\partial v v e l}$ and the bottom plots $(\mathrm{e}-\mathrm{h})$ are same as top plots, but for $\mathbf{J}=\mathrm{SST}$. The gray lines mark zero contours.

about $100 \mathrm{~m}$ of the surface, but negative lobes and deeper structures emerge slowly in comparison to SSH. As can be seen in Figure 8, there are deep negative sensitivities for both SSH and SST near the Yucatan coast, but the light blue shading represents only very small sensitivity (Figures $8 \mathrm{e}-8 \mathrm{~h})$, merely marking the boundary between negative and zero sensitivity.

[30] In order to sample the influence of ocean state on the sensitivity of LC dynamics, adjoint sensitivities were computed for up to 60 days prior to two additional target dates: (i) before eddy separation (start day: 1 March, target day: 29 April 2010), and (ii) after eddy separation (start day: 1 May, target day: 29 June 2010), where the spatial average for $\mathbf{J}$ is identical to the eddy separation experiment. In other words, the adjoint experiments used identical cost functions ( $\mathbf{J})$ but for target dates before and after the MITgcm-IAS simulated Eddy-F separation on 30 May 2010 (Figure 5). The temporal summation and some statistics of time evolution of adjoint sensitivities across the $\mathrm{YC}$ are compared for the three scenarios in Figures 9 and 10, respectively. Figure 9 compares the temporal summation of the sensitivity per unit depth to vvel across the $\mathrm{YC}$ at $21.85^{\circ} \mathrm{N}$ over the first 30 days of adjoint backward integration for the three scenarios for SSH and SST. All three cases show significant differences, meaning that the sensitivity depends on the different states of the LC, but the "after eddy separation" sensitivities (when the cost function represents the extension of the LC front) are very different from the other two cases for both SSH and SST. The cumulative influence of the YC meridional velocity on the LC extension for SSH is much stronger and deeper than for SST in both the "before eddy separation" and "during eddy separation" scenarios, where the "during eddy separation" scenario shows a less pronounced effect than the "before eddy separation" scenario due to the separating phase of the LCE. The "after eddy separation" case has a direct link between YC dynamics and the cost function, since extension of the LC front warms the target region, so the YC has stronger control of SST compared to when there is a large attached eddy or separation underway. We hypothesize that the sensitivity for SST penetrates deeply for the "after eddy separation" because the total dynamics of the LC extension apply, rather than advection of temperature by the fast core of the LC. On the other hand, the integrated SST sensitivity appears very different to the SSH sensitivity, so the SSH and SST cost functions are not equal proxies for the LC extension.

[31] The time evolution of sensitivity to vvel across the $\mathrm{YC}$ is explored in Figure 10. To simplify the plot, the 

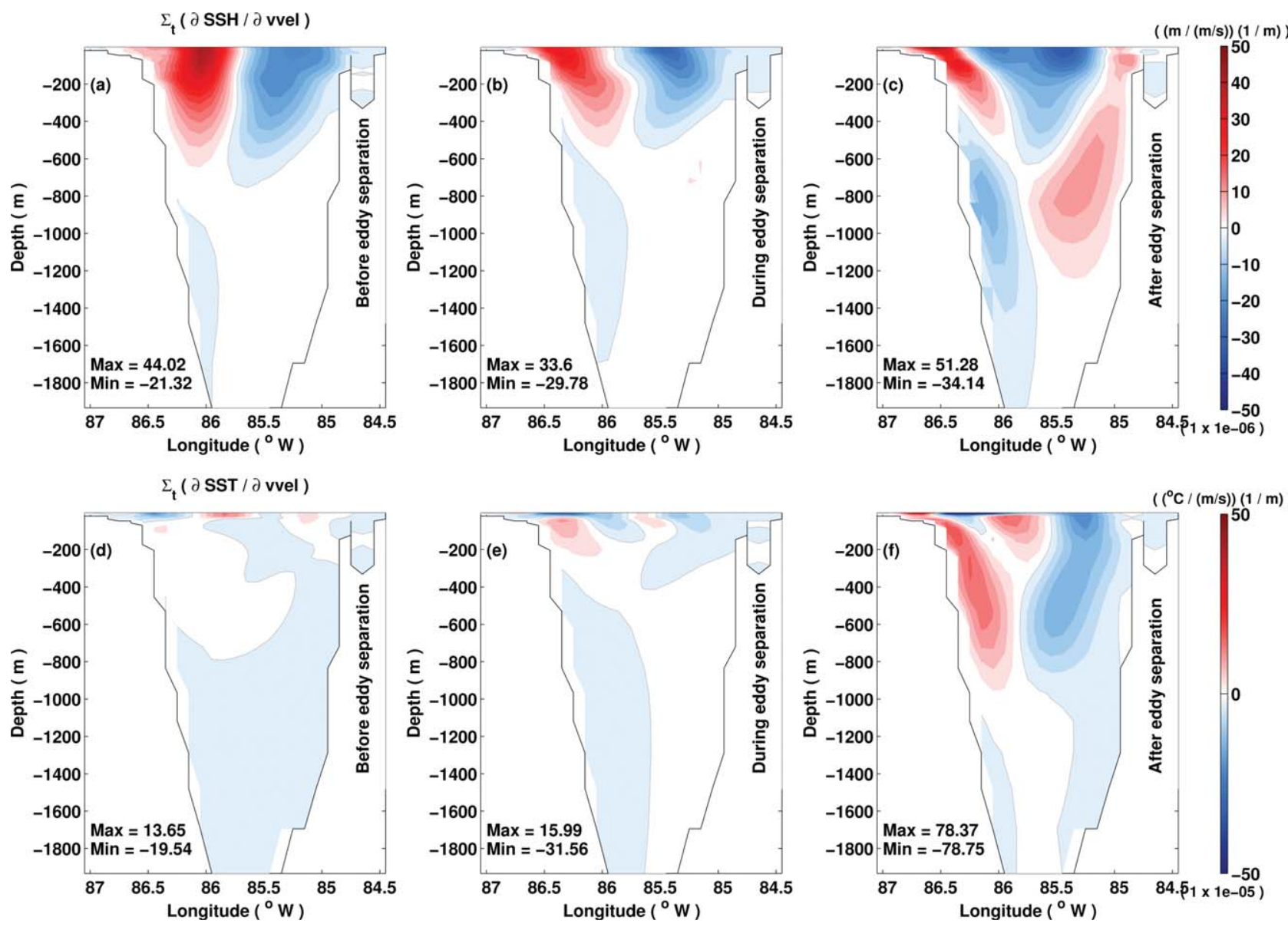

Figure 9. Temporal summation $\left(\sum_{t}\right)$ of the adjoint sensitivities per unit depth for the first 30 days of adjoint simulation across the $\mathrm{YC}$ at $21.85^{\circ} \mathrm{N}$ for $\mathbf{J}=\mathrm{SSH}$ and $\mathbf{J}=\mathrm{SST}$ for the three adjoint sensitivity experiments: (i) before eddy separation (1 March to 29 April 2010), (ii) during eddy separation (1 May to 30 May 2010), and (iii) after eddy separation (1 May to 29 June 2010). The top plots (a-c) shows $\sum_{t}\left[\frac{\partial \mathrm{SSH}}{\partial v v e l}\right]$ and the bottom plots $(\mathrm{d}-\mathrm{f})$ are same as top plots, but for $\mathbf{J}=\mathrm{SST}$. The gray lines mark zero contours.

sensitivities were represented as the square root of summed squares of sensitivities per unit depth: $\left[\frac{1}{n} \sum_{x z}\left[\frac{\partial \mathbf{J}}{\partial v v e l}\right]^{2}\right]^{0.5}$, where $n$ is the number of grid points, for both SSH and SST for each scenario. The SSH and SST sensitivities grow with approximately the same timescales, but SST sensitivities generally decrease faster, consistent with the dissipation of SST effects through mixing and the dominance of atmospheric forcing of SST. The "after eddy separation" case is again an exception to this generalization, with both SSH and SST sensitivity holding nearly constant, corresponding to slow, consistent LC extension. The SSH sensitivity is much higher for the "during eddy separation" than for the others, and the occurrence of its maximum value corresponds to the beginning of the Eddy-F detachment on 21 May 2010 in the MITgcm-IAS simulation (not shown). The 30 day duration of sensitivity in the YC suggests that some long-term predictability is available for models with the YC as a boundary condition, although sensitivity does propagate strongly upstream into the Caribbean Sea (Figure 6).
[32] Additional adjoint sensitivity experiments for LCE separation events in the years 2004 and 2005 were performed using the same model setup as that for the 2010 experiments. The adjoint model solutions for other LCE separation experiments (not shown) vary depending on the forward model trajectory, but are in general agreement with the 2010 sensitivities, showing upstream propagation of sensitivities for both $\mathbf{J}=S S H$ and $\mathbf{J}=S S T$ and $\mathrm{SSH}$ sensitivity penetrating deeper in the YC than SST.

\subsubsection{Sensitivity to Winds}

[33] The influence of local atmospheric wind forcing on the LC dynamics was examined using adjoint sensitivities to zonal (uwind) and meridional (vwind) winds for both $\mathbf{J}=S S H$ and $\mathbf{J}=S S T$ for all three scenarios. The spatial pattern of positive and negative sensitivities (not shown) to winds (uwind and vwind) were qualitatively similar to that to surface velocities (uvel and vvel), respectively (Figure 6 ), but were quantitatively smaller. When the adjoint sensitivities to winds and to surface velocities were normalized by the corresponding standard deviations, assuming a uniform standard deviation over the domain of $2 \mathrm{~m} \mathrm{~s}^{-1}$ for 

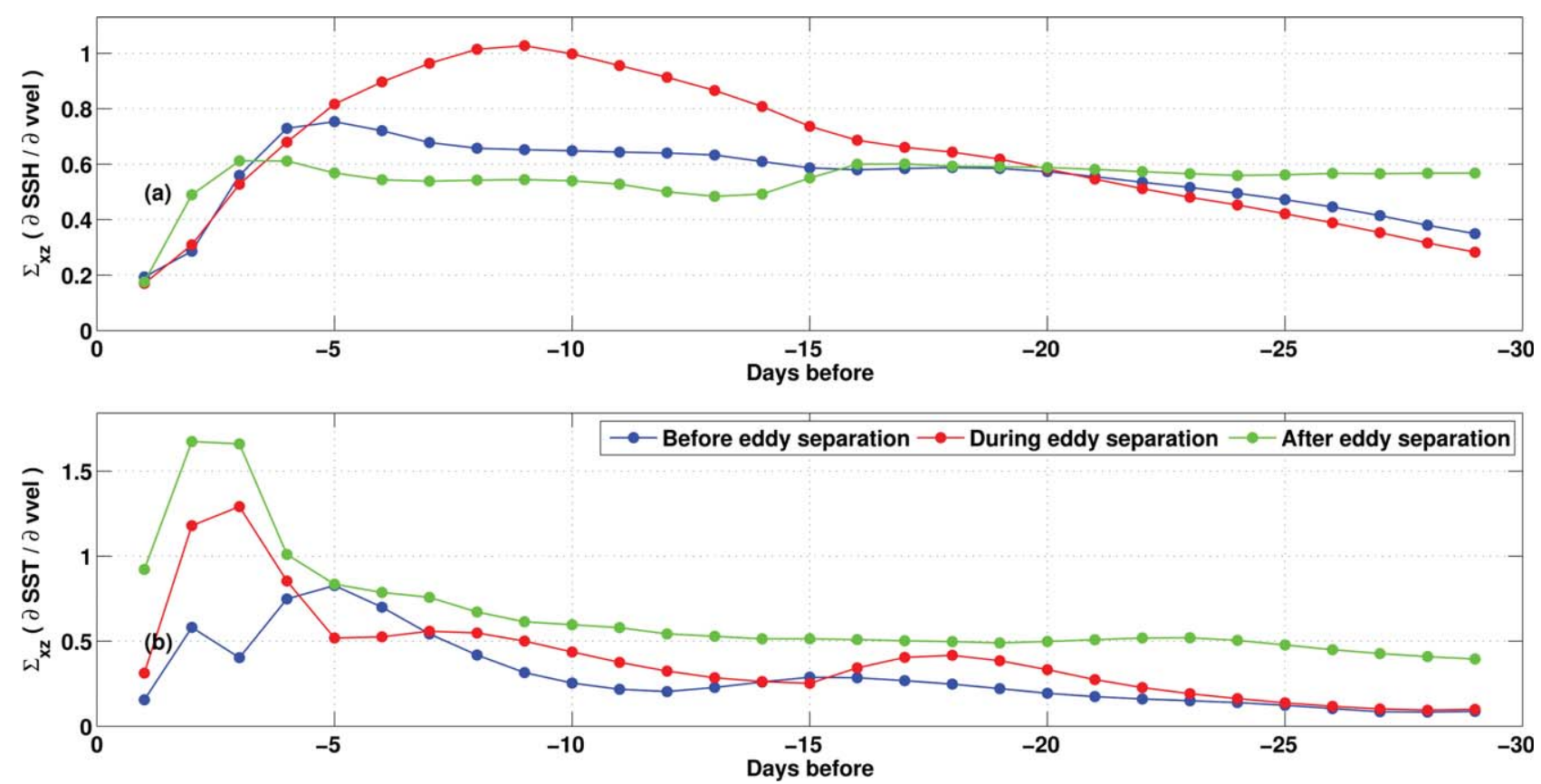

Figure 10. Temporal evolution $\left(\sum_{x z}\right)$ of the adjoint sensitivities to vvel for the first 30 days of adjoint simulation across the YC cross section for $\mathbf{J}=\mathrm{SSH}$ and $\mathbf{J}=\mathrm{SST}$ for the three adjoint sensitivity experiments: (i) before eddy separation (1 March to 29 April 2010), (ii) during eddy separation (1 May to 30 May 2010), and (iii) after eddy separation (1 May to 29 June 2010). The top plot shows the square root of summed squares of sensitivities per unit depth, $\left[\frac{1}{n} \sum_{x z}\left[\frac{\partial \mathbf{J}}{\partial v v e l}\right]^{2}\right]^{0.5}$, where $n$ is the number of grid points, and the bottom plot is same as top plot, but for $\mathbf{J}=\mathrm{SST}$. The sensitivities were scaled by $1 \times$ $10^{6}$ for SSH and $1 \times 10^{5}$ for SST.

winds and $0.2 \mathrm{~m} \mathrm{~s}^{-1}$ for velocities, the weighted sensitivities to winds were approximately 100 times smaller than to surface velocities, for both SSH and SST cost functions. These results suggest that the LC extension and eddy shedding are less sensitive to local wind forcing, in agreement with the 5 year model simulations with different (NCEP/ NCAR-R1 and QuikSCAT) wind products (section 2.1).

\subsection{Florida Strait Transport Sensitivity Analysis}

[34] The sensitivity of Florida Strait transport ( $x-z$ vertical section between Jupiter and Settlement Point, Florida; at $27^{\circ} \mathrm{N}$, Figure 1) was computed with respect to model controls for up to 60 days. The cost function was model transport across $80^{\circ}-78^{\circ} \mathrm{W}, 27^{\circ} \mathrm{N}, 0-1000 \mathrm{~m}$ averaged over the target day, 29 June 2010, after Eddy-F separation. Figure 11 compares the horizontal sections of sensitivities of Florida Strait transport $\left(\mathbf{J}=\mathrm{TR}_{27 \mathrm{~N}}\right)$ (locations are indicated in Figure 1) to uvel and vvel surface velocities $\left(\frac{\partial \mathrm{TR}_{27 \mathrm{~N}}}{\partial u v e l}\right.$ and $\left.\frac{\partial \mathrm{TR}_{27 \mathrm{~N}}}{\partial v v e l}\right)$ during the first week of adjoint backward integration. The adjoint sensitivity to uvel shows positive sensitivity tracing back into the GoM, especially where the current is zonal, so eastward uvel perturbations accelerate the flow. Negative sensitivity traces through the side channels: North West Providence Channel (NWPC), south of Settlement Point, and the Old Bahama Channel (OBC), north of Cuba, corresponding to westward flow in these channels which adds to the transport. Positive sensitivities north of Settlement Point can be understood simply as cre- ating a divergence north of the chosen section at $27^{\circ} \mathrm{N}$. The sensitivities to vvel show upstream and downstream propagation, strongest when the current is heading north, again consistent with simple mass balance. The sensitivities in the NWPC and OBC are similar, signed according to the orientation of the channel to create convergence south of the transport latitude or divergence north. This influence of the flow through the side channels (NWPC and OBC) on the Florida Strait transport variability is in line with the observational findings reported by Hamilton et al. [2005] and Sheinbaum et al. [2002]. At the latitude of the Florida cable station, a significant dipole in vvel sensitivity is visible on days 5 and 7, seeming to indicate that offshore migration of the current would increase northward transport after about a week.

\section{Forward Sensitivity Analysis}

[35] A forward model perturbation study was also performed to examine the sensitivity evolution in a more familiar way. The linearity of the response was checked by differencing the responses to positive and negative perturbations. The purpose was to check the adjoint results, not to create significant changes in the LC system, so the perturbation magnitudes were made as small as possible while maintaining adequate significance in the differences compared to rounding noise. The $\mathrm{SSH}$ in the $\mathrm{YC}$ region was changed by $\pm 5 \mathrm{~cm}$ in one experiment, while near-surface 

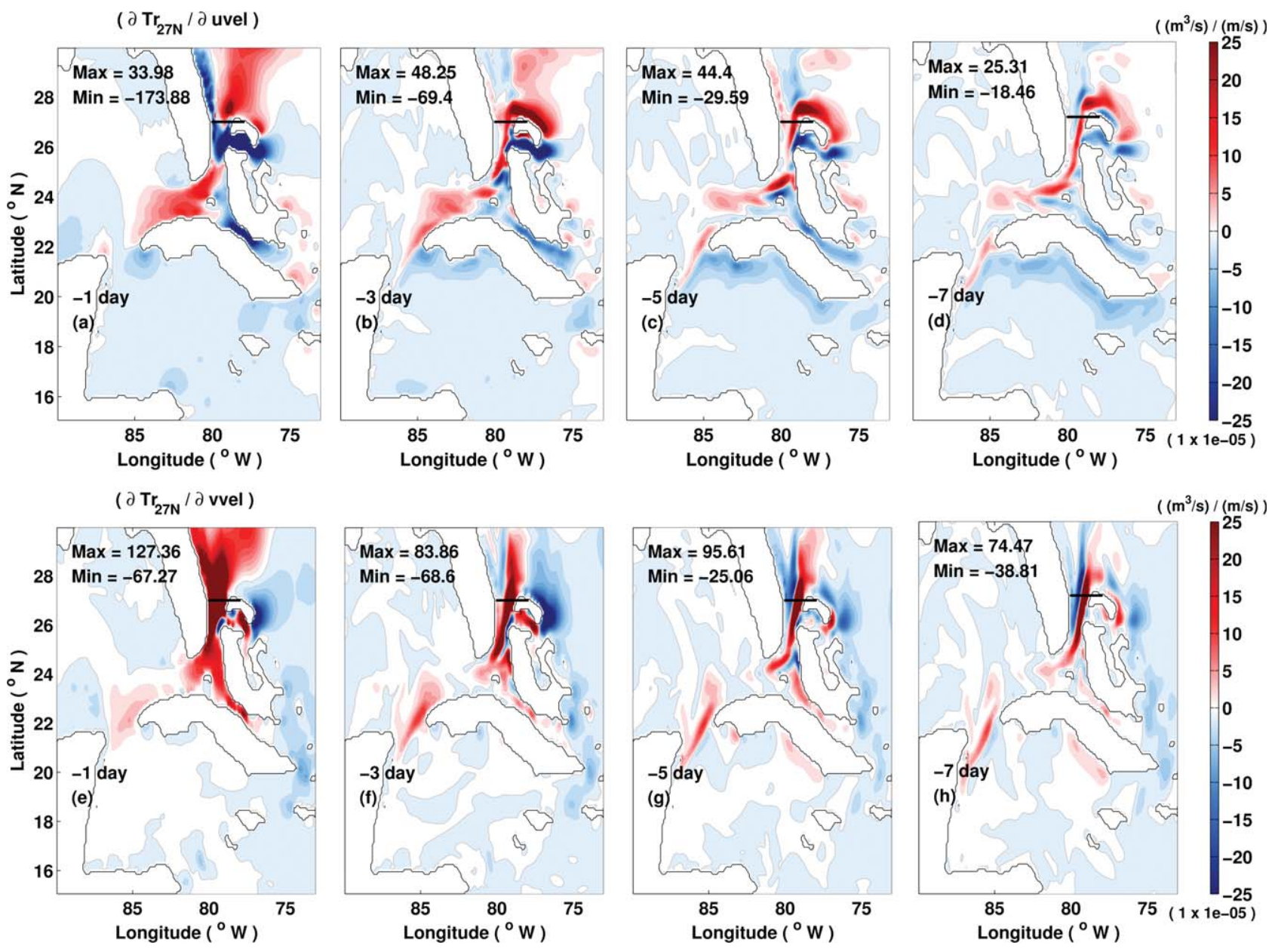

Figure 11. Evolution of the adjoint sensitivity, backward in time (from left to right) for $\mathbf{J}=\mathrm{TR}_{27 \mathrm{~N}}$ with respect to $u v e l$ and vvel at the surface for the first week of backward integration. The top plots (a-d) shows $\frac{\partial \mathrm{TR}_{27 \mathrm{~N}}}{\partial u v e l}$ and the bottom plots $(\mathrm{e}-\mathrm{h})$ shows $\frac{\partial \mathrm{TR}_{27 \mathrm{~N}}}{\partial v v e l}$. The thick black line marks the $x-z$ section across which $\mathbf{J}$ is computed, and the gray lines mark zero contours.

velocity $(0-100 \mathrm{~m})$ vvel was changed by $\pm 10 \mathrm{~cm} \mathrm{~s}^{-1}$ in another, both with isotropic Gaussian $1^{\circ} e$-folding scales. The perturbations were centered at $85.5^{\circ} \mathrm{W}, 21.85^{\circ} \mathrm{N}$ for $\mathrm{SSH}$ and $85.5^{\circ} \mathrm{W}, 21.85^{\circ} \mathrm{N}, 50 \mathrm{~m}$ for vvel. The SSH and vvel perturbations were introduced into the model initial conditions and integrated forward for up to 60 days, starting from 1 May 2010.

[36] To estimate nonlinearity, the SSH differences from the reference and two (positive and negative) perturbation simulations are combined into first and second differences: $\delta H_{1}=\frac{\left(\delta h_{1}-\delta h_{2}\right)}{2}$ and $\delta H_{2}=\frac{\left(\delta h_{1}+\delta h_{2}\right)}{2}$, where $\delta h_{1}=h_{+}-h_{0}$ and $\delta h_{2}=h_{-}-h_{0}$. Here, $h_{+}$is the SSH with a positive perturbation, $h_{0}$ is the SSH with no perturbation, and $h_{-}$is the SSH with a negative perturbation. At every point, the differences between a perturbed and the unperturbed simulation can be expressed as a Taylor expansion in powers of the perturbation. The first term is linear, the second term is quadratic, and so on. The second difference $\left(\delta H_{2}\right)$ with respect to the amplitude of a perturbation is an approximate indicator of when the first nonlinear term in the expansion becomes important. The top two plots of Figure 12 show the first week evolution of $\delta H_{1}$ and $\delta H_{2}$ for SSH perturbations in the $\mathrm{YC}$ region, and the bottom two plots show the later evolution of the same two quantities in weekly snapshots. SSH differences between perturbed and unperturbed model simulations for vvel velocity perturbations at the $\mathrm{YC}$ are shown in Figure 13. The SSH differences propagate northward into the GoM following the LC signature for both SSH and vvel perturbation experiments.

[37] The figures show that nonlinearity $\left(\delta H_{2}\right)$ remains less than $10 \%$ of the linear term $\left(\delta H_{1}\right)$ during the first three weeks of the simulation. The perturbations become strongly nonlinear toward the end of the 2 month simulation, even though the strength of the perturbation does not grow without bound, probably due to the viscosity and model resolution of these experiments. For perturbation experiments using the same higher viscosity (not shown) used in the adjoint model, the nonlinearity remains small. The $\delta \mathrm{H}_{2}$ perturbations evolve similarly at high viscosity, but fade away slightly faster, to less than $10 \%$ of $\delta H_{1}$ by the end of the first week, and nearly zero after 2 weeks.

[38] The forward model vvel perturbation experiment shows downstream propagation of SSH differences which match with the upstream propagation (backward in time) of the adjoint sensitivities. This was quantitatively tested for the eddy separation event by convolving the adjoint 

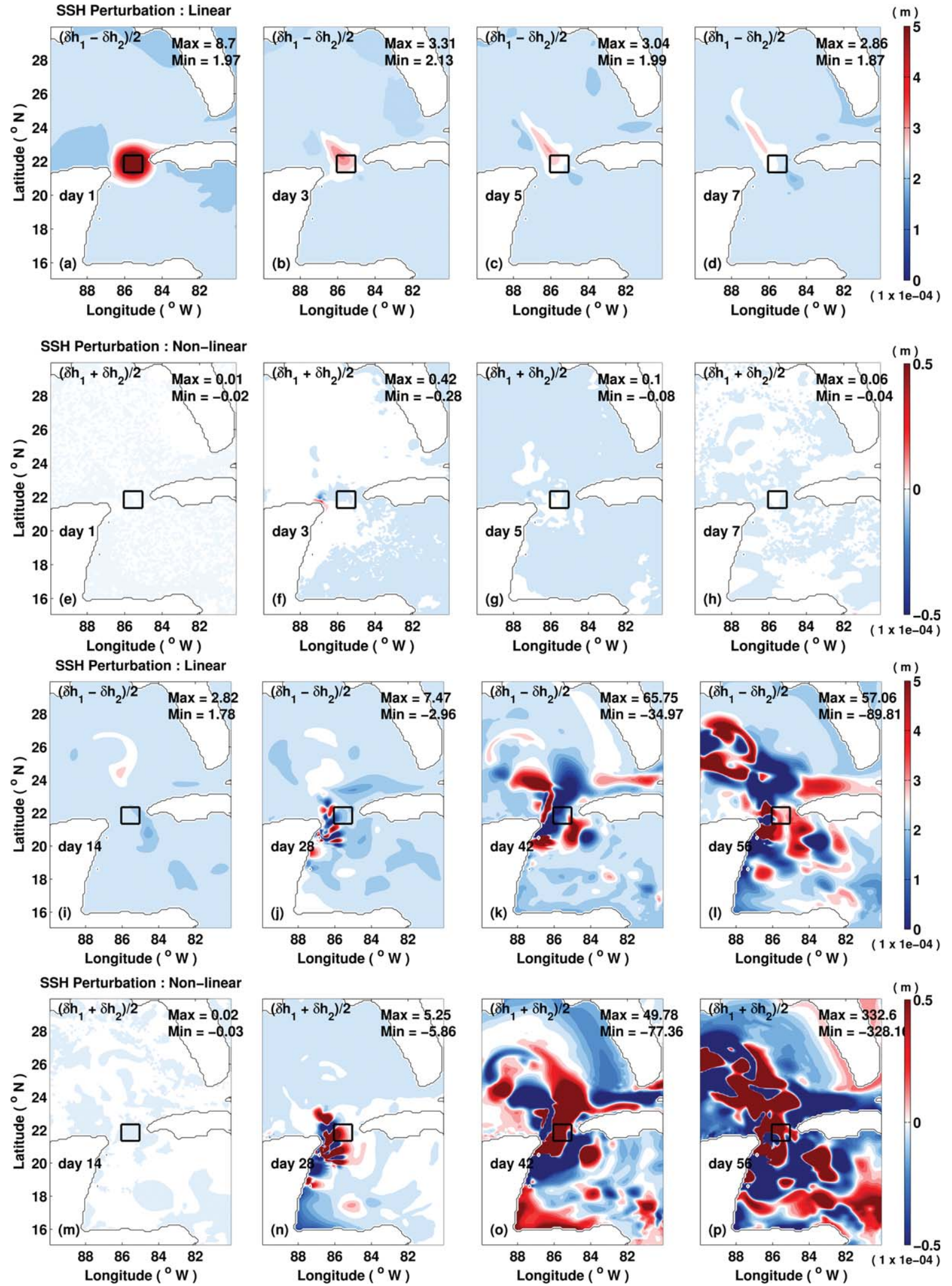

Figure 12. Evolution of the SSH differences for the model SSH perturbation simulation. The plots (a-d) and (i-l) show $\delta H_{1}=\frac{\left(\delta h_{1}-\delta h_{2}\right)}{2}$, and (e-h) and (m-p) show $\delta H_{2}=\frac{\left(\delta h_{1}+\delta h_{2}\right)}{2}$, where $\delta h_{1}=h_{+}-h_{0}$ and $\delta h_{2}=h_{-}-h_{0}$. The black box marks the perturbation location. 

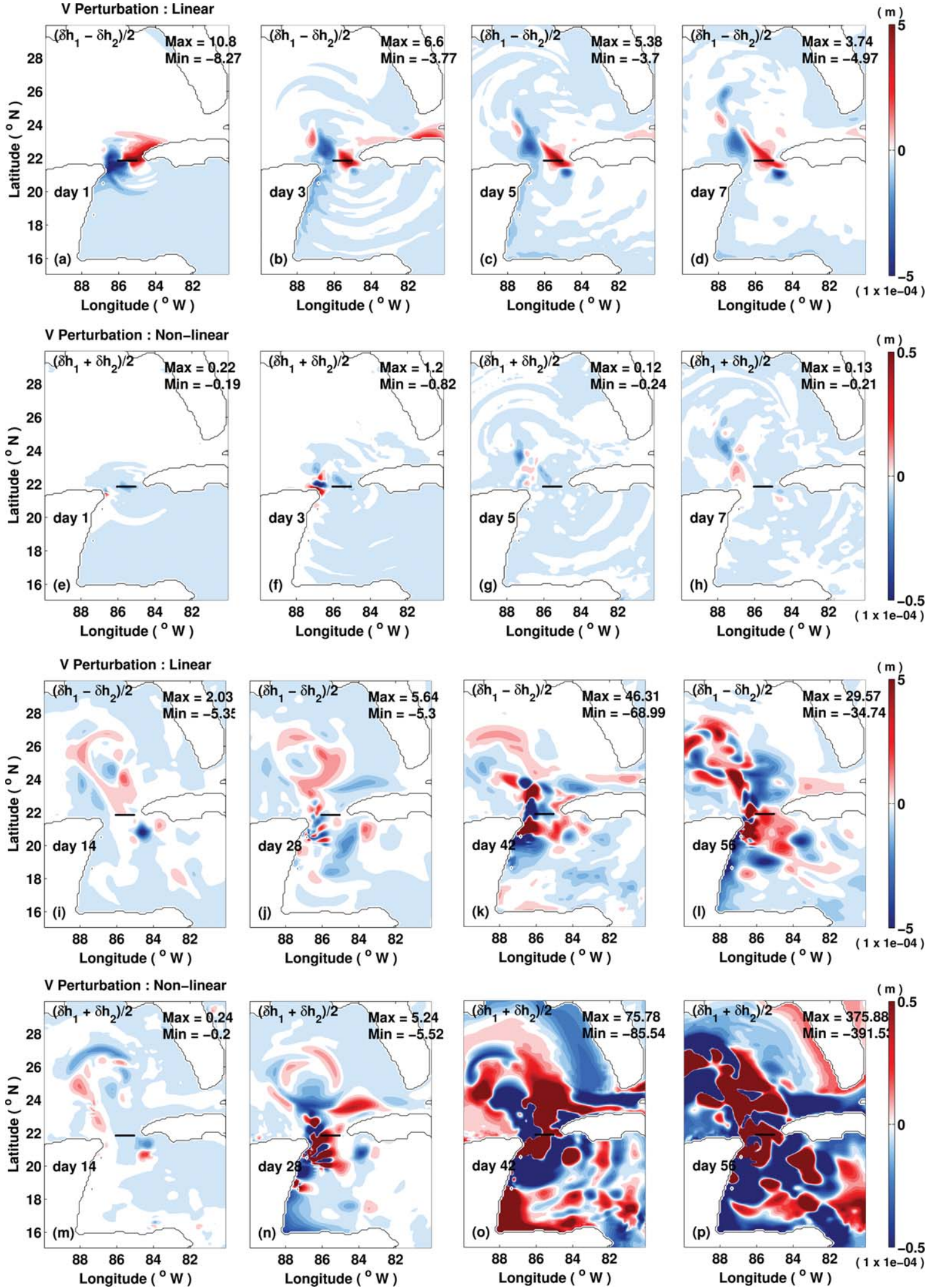

Figure 13. Evolution of the SSH differences for the model vvel perturbation simulation. Figure caption remain the same as for Figure 12. The thick black line marks the $x-z$ section for vvel perturbation location. 
sensitivities $\left(\frac{\partial \mathrm{SSH}}{\partial v \mathrm{v} e l}\right)$ with the vvel perturbation over the YC cross section and comparing this estimate with the SSH differences obtained from the reference and the perturbation simulations. The perturbations agree within $1 \%$ for the first 3 days at either viscosity, and the differences again become less than $1 \%$ only for the high viscosity case during the week before the adjoint target date of 30 May, as expected. While these sorts of gradient checks are automatically performed as part of the MITgcm and ECCO system tests, this test also measures the linearity of the sensitivity evolution over a 30 day period.

\section{Discussion and Conclusions}

[39] The MITgcm-IAS adjoint model was used to investigate the sensitivities of the LC and Florida Strait transport to control variables including model state at earlier times and atmospheric forcing. This study addresses the influence of the YC through-flow and LCFEs on the LC dynamics and eddy shedding in the GoM. As the first step to evaluate the MITgcm-IAS model capability for simulating the LC system and eddy shedding in the GoM, the MITgem-IAS model initialized using assimilated HYCOM $1 / 12^{\circ}$ global analysis was integrated forward for 5 years using a variety of forcing products, including NCEP/NCAR-R1 winds and atmospheric fluxes as well as a combination of QuikSCAT SeaWinds and NCEP/NCAR-R1 atmospheric fluxes, and used assimilated HYCOM for the open boundary conditions, and climatological run-off fluxes. The simulations were compared to satellite measurements of SSH and SST, and observed transport variability at the northern end of the Straits of Florida. The forward model-data comparison showed a LC system and eddy shedding at intervals varying from 6 to 9 months, including occasional detachment and reattachment of the LCE. The modeled LC showed a negative bias of $\sim 1^{\circ}$ in its westward and northward extension into the GoM basin compared to AVISO observations, indicating that it did not extend as far as observed, and the LC eddy shedding in the model was too periodic compared to AVISO observations. This regularity in the LC eddy shedding in the model suggests that the mechanisms leading to eddy separation are simplified and repeatable in the model and can serve as a laboratory for examining the factors that control a simple but generic LC eddy separation. This adjoint model study can be considered as a first step for tracing the ocean influences leading to LC eddy separation in the GoM, although the sensitivity analysis discussed here will not hold for all LC eddy separations.

[40] Five year forward model simulations with two wind products (NCEP/NCAR-R1 and QuikSCAT) with significantly different winds yielded similar results with respect to LC evolution suggesting that the local wind forcing is not the major control of the LC evolution and eddy shedding in the GoM.

[41] Cost function targets for the LC adjoint sensitivity analysis were mean SSH and SST in a $2^{\circ} \times 2^{\circ}$ box centered on the separating neck of the LC and LCE. These served as proxies for the separation and extension of the LC. The adjoint sensitivity analysis of the LC revealed details of how the LC extension and eddy shedding is affected by the upstream flow structure, including enhanced separation from cyclonic vorticity anomalies in a LCFE to the east of the LC and in the YC. Sensitivities of the LC for SST generally remain closer to the surface than for $\mathrm{SSH}$ and are advected by the strong surface currents, whereas LC sensitivities for SSH extend deeper in the YC than for SST. Sensitivities of the LC to uvel and vvel showed the influence of the LCFE on the LCE separation for both SSH and SST.

[42] Although the YC is an obvious control point, the sensitivity is smoothly varying through and across the channel, suggesting that observations need not be dense or focused on the channel if LC prediction is a goal. Sensitivity shows significant depth dependence, especially for the "after eddy separation" case where the cost function represents simple LC extension. Given the generally quasi-geostrophic balance in this region, the sensitivity to velocity implies a sensitivity to density (and temperature and salinity). This information could be used to select observation points to enhance the LC predictability. For example, for eddy separation, surface currents have an important influence, but with large horizontal scales in the YC and very small scales in the LCFE. The significant change in the adjoint sensitivity patterns before and after eddy separation shows that deeper measurements contain information for predicting LC extension.

[43] Not surprisingly, LC sensitivity is strongly modulated by different states of the LC such as before, during, and after LCE separation, with strongest sensitivity generally seen during the eddy separation event. One simple outcome of this study is the relatively long-time lags ( $\sim 30$ days) at which the YC region exerts control over the LC evolution. This suggests that predictability would be available at these timescales from measurements in the YC and even in the Caribbean Sea. The adjoint sensitivities of the LC SSH and SST to atmospheric wind forcing are much weaker than to surface currents, suggesting that the LC dynamics are less affected by the local wind forcing in the GoM than by internal dynamics, which is supported by the results of the forward model wind forcing experiment.

[44] Sensitivities were also calculated for the Florida Strait transport at $27^{\circ} \mathrm{N}$. The sensitivity in the preceding few days behaves in line with intuitive mass balance considerations, as has been suggested by observations. The sensitivity also suggests that offshore migration of the horizontal current structure would increase the northward transport a week later.

[45] In the forward sensitivity analysis using $\mathrm{SSH}$ and vvel perturbations in the $\mathrm{YC}$, the growth of perturbations is moderate for the first 3 weeks, but accelerates later in the 2 month simulation. Nonlinearity remains less than $10 \%$ of the linear term for the first 3 weeks of the simulation but becomes larger than the linear term at the end of the 2 month simulation. Although the adjoint sensitivities were tested by forward model perturbation experiments, a more comprehensive test of the adjoint is its use in state estimation. In that application, if the gradients (i.e., adjoint sensitivities) are not correct, the model-observation misfit cost function cannot be reduced, and the estimate will not be able to fit the observations.

[46] The application of this adjoint model in fourdimensional variational assimilation (4D-VAR) to produce dynamically consistent ocean state estimates for analysis and forecasts of the circulation of the GoM is discussed in the companion manuscript [Gopalakrishnan et al., 2013]. The 
MITgcm-IAS adjoint model is used to fit along-track SSH observations, separated into temporal mean and anomalies, and gridded SST observations for 2 months by adjusting model temperature and salinity initial conditions, open boundary conditions, and atmospheric forcing fields. The optimized state obtained by iterative minimization is tested by predicting the $\mathrm{LC}$ evolution for 2 months from the end of the assimilation period. The model forecast was tested for several LC eddy separation events, including Eddy-F in May 2010 during the Deepwater Horizon (DwH) oil spill accident in the GoM [Gopalakrishnan et al., 2013].

[47] Acknowledgments. The authors gratefully acknowledge several data sources: NCEP/NCAR reanalysis, the HYCOM consortium, and the ECCO consortium, including MIT, JPL, and the University of Hamburg.

\section{References}

Abascal, A., J. Sheinbaum, J. Candela, J. Ochoa, and A. Badan (2003), Analysis of flow variability in the Yucatan Channel, J. Geophys. Res., 108(C12), 3381, doi:10.1029/2003JC001922.

Badan, A., J. Candela, J. Sheinbaum, and J. Ochoa (2005), Upper-layer circulation in the approaches to Yucatan Channel, Geophys. Monogr. Am. Geophys. Union, 161, 57-69.

Baringer, M., and J. Larsen (2001), Sixteen years of Florida current transport at $27^{\circ} \mathrm{N}$, Geophys. Res. Lett., 28(16), 3179-3182.

Bunge, L., J. Ochoa, A. Badan, J. Candela, and J. Sheinbaum (2002), Deep flows in the Yucatan Channel and their relation to changes in the Loop Current extension, J. Geophys. Res., 107(C12), 3233, doi:10.1029/ 2001JC001256.

Candela, J., J. Sheinbaum, J. Ochoa, A. Badan, and R. Leben (2002), The potential vorticity flux through the Yucatan Channel and the Loop Current in the Gulf of Mexico, Geophys. Res. Lett., 29(22), 2059, doi: 10.1029/2002GL015587.

Chassignet, E., H. Hurlburt, O. Smedstad, G. Halliwell, P. Hogan, A. Wallcraft, R. Baraille, and R. Bleck (2007), The HYCOM (HYbrid Coordinate Ocean Model) data assimilative system, J. Mar. Syst., 65(1-4), 60-83.

Chérubin, L., Y. Morel, and E. Chassignet (2006), Loop current ring shedding: The formation of cyclones and the effect of topography, J. Phys. Oceanogr., 36(4), 569-591.

Cochrane, J. (1972), Separation of an anticyclone and subsequent developments in the Loop Current (1969), Contrib. Phys. Oceanogr. Gulf Mex., 2, 91-106.

Elliott, B. (1982), Anticyclonic rings in the Gulf of Mexico, J. Phys. Oceanogr., 12(11), 1292-1309.

Errico, R. (1997), What is an adjoint model?, Bull. Am. Meteorol. Soc., $78(11), 2577-2592$.

Ezer, T., L. Oey, and H. Lee (2002), Simulation of velocities in the Yucatan Channel, in Proceedings of the OCEANS'02 MTS/IEEE, Biloxi, Mississippi, vol. 3, pp. 1467-1471, IEEE.

Ezer, T., L. Oey, H. Lee, and W. Sturges (2003), The variability of currents in the Yucatan Channel: Analysis of results from a numerical ocean model, J. Geophys. Res., 108(C1), 3012, doi:10.1029/2002JC001509.

Forristall, G., K. Schaudt, and C. Cooper (1992), Evolution and kinematics of a Loop Current eddy in the Gulf of Mexico during 1985, J. Geophys. Res., 97(C2), 2173-2184.

Fratantoni, P., T. Lee, G. Podesta, and F. Muller-Karger(1998), The influence of Loop Current perturbations on the formation and evolution of Tortugas eddies in the southern straits of Florida, J. Geophys. Res., 103(C11), 24,759-24,779.

Fukumori, I., T. Lee, B. Cheng, and D. Menemenlis (2004), The origin, pathway, and destination of Niño-3 water estimated by a simulated passive tracer and its adjoint, J. Phys. Oceanogr., 34, 582-604.

Galanti, E., and E. Tziperman (2003), A Midlatitude-ENSO teleconnection mechanism via baroclinically unstable long Rossby waves, J. Phys. Oceanogr., 33(9), 1877-1888.

Giering, R., and T. Kaminski (1998), Recipes for adjoint code construction, ACM Trans. Math. Software, 24(4), 437-474.

Gopalakrishnan, G., B. D. Cornuelle, I. Hoteit, D. L. Rudnick, and W. B. Owens (2013), State estimates and forecasts of the loop current in the Gulf of Mexico using the MITgcm and its adjoint, J. Geophys. Res. Oceans, 118, doi:10.1002/jgrc.20239.
Hamilton, P. (1992), Lower continental slope cyclonic eddies in the central Gulf of Mexico, J. Geophys. Res., 97(C2), 2185-2200.

Hamilton, P., T. Berger, and W. Johnson (2002), On the structure and motions of cyclones in the northern Gulf of Mexico, J. Geophys. Res., 107(C12), 3208, doi:10.1029/1999JC000270.

Hamilton, P., J. Larsen, K. Leaman, T. Lee, and E. Waddell (2005), Transports through the straits of Florida, J. Phys. Oceanogr., 35(3), 308-322.

Heimbach, P., C. Hill, and R. Giering (2002), Automatic generation of efficient adjoint code for a parallel Navier-Stokes solver, Proceedings of the International Conference on Computational Science-ICCS 2002, Amsterdam, The Netherlands, vol. 230, Part II, pp. 1019-1028, Springer.

Hill, C., V. Bugnion, M. Follows, and J. Marshall (2004), Evaluating carbon sequestration efficiency in an ocean circulation model by adjoint sensitivity analysis, J. Geophys. Res., 109, C11005, doi:10.1029/ 2002JC001598.

Hoteit, I., B. Cornuelle, A. Kohl, and D. Stammer (2005), Treating strong adjoint sensitivities in tropical eddy-permitting variational data assimilation, Q. J. R. Meteorol. Soc., 131(613), 3659-3682.

Hoteit, I., B. Cornuelle, S. Kim, G. Forget, A. Kohl, and E. Terrill (2009), Assessing 4D-VAR for dynamical mapping of coastal high-frequency Radar in San Diego, Dyn. Atmos. Oceans, 48(1-3), 175-197.

Hoteit, I., B. Cornuelle, and P. Heimbach (2010), An eddy-permitting, dynamically consistent adjoint-based assimilation system for the tropical Pacific: Hindcast experiments in 2000, J. Geophys. Res. Oceans, 115(C3), C03001, doi:10.1029/2009JC005437.

Hoteit, I., T. Hoar, G. Gopalakrishnan, N. Collins, J. Anderson, B. Cornuelle, and P. Heimbach (2012), A MITgcm/DART ensemble analysis and prediction system with application to the Gulf of Mexico, Dyn. Atmos. Oceans, 63(2013), pp. 1-23.

Hurlburt, H. (1986), Dynamic transfer of simulated altimeter data into subsurface information by a numerical ocean model, J. Geophys. Res. Oceans, 91(C2), 2372-2400.

Hurlburt, H., and J. Thompson (1980), A numerical study of Loop Current intrusions and eddy shedding, J. Phys. Oceanogr., 10(10), 1611-1651.

Ichiye, T. (1962), Circulation and water mass distribution in the Gulf of Mexico, Geofis. Int., 2(3), 47-76.

Kalnay, E., M. Kanamitsu, R. Kistler, W. Collins, D. Deaven, L. Gandin, M. Iredell, S. Sana, G. White, J. Woollen, and others (1996), The NCEP/ NCAR 40 reanalysis project, Bull. Am. Meteorol. Soc., 77, 437-471.

Kirwan, A., W. Merrell, R. Whitaker, and J. Lewis (1984), Lagrangian observations of an anticyclonic ring in the western Gulf of Mexico, J. Geophys. Res., 89(C3), 3417-3424.

Kohl, A., D. Stammer, and B. Cornuelle (2007), Interannual to decadal changes in the ECCO global synthesis, J. Phys. Oceanogr., 37(2), 313337.

Large, W., and S. Pond (1981), Open ocean momentum flux measurements in moderate to strong winds, J. Phys. Oceanogr., 11(3), 324-336.

Large, W., J. McWilliams, and S. Doney (1994), Oceanic vertical mixing: A review and a model with a nonlocal boundary layer parameterization, Rev. Geophys., 32(4), 363-403.

Le Hénaff, M., V. Kourafalou, Y. Morel, and A. Srinivasan (2012), Simulating the dynamics and intensification of cyclonic loop current frontal eddies in the Gulf of Mexico, J. Geophys. Res., 117, C02034, doi:10.1029/ 2011JC007279.

Leben, R. (2005), Altimeter-derived loop current metrics, Geophys. Monogr. Am. Geophys. Union, 161, 181-201.

Levitus, S., T. Boyer, M. Conkright, T. O’Brien, J. Antonov, C. Stephens, L. Stathoplos, D. Johnson, and R. Gelfeld (1998), World ocean database 1998, NOAA Atlas Nesdis, 18, 346 pp.

Li, X., and C. Wunsch (2004), An adjoint sensitivity study of chlorofluorocarbons in the north Atlantic, J. Geophys. Res., 109, C01007, doi: 10.1029/2003JC002014.

Losch, M., and P. Heimbach (2007), Adjoint sensitivity of an ocean general circulation model to bottom topography, J. Phys. Oceanogr., 37(2), 377393.

Marotzke, J., R. Giering, K. Zhang, D. Stammer, C. Hill, and T. Lee (1999), Construction of the adjoint MIT ocean general circulation model and application to Atlantic heat transport sensitivity, J. Geophys. Res., 104(C12), 29,529-29,547.

Marshall, J., A. Adcroft, C. Hill, L. Perelman, and C. Heisey (1997), A finite-volume, incompressible Navier Stokes model for studies of the ocean on parallel computers, J. Geophys. Res., 102(C3), 5753-5766.

Maul, G., D. Mayer, and S. Baig (1985), Comparisons between a continuous 3-year current-meter observation at the sill of the Yucatan Strait, 


\section{GOPALAKRISHNAN ET AL.: ADJOINT SENSITIVITY OF LOOP CURRENT}

satellite measurements of Gulf Loop Current area, and regional sea level, J. Geophys. Res., 90, 9089-9096.

Mazloff, M., P. Heimbach, and C. Wunsch (2010), An eddy-permitting southern ocean state estimate, J. Phys. Oceanogr., 40, 880-899.

Menemenlis, D., I. Fukumori, and T. Lee (2005), Using Green's functions to calibrate an ocean general circulation model, Mon. Weather Rev. 133(5), 1224-1240

Moore, A., H. Arango, E. Di Lorenzo, A. Miller, and B. Cornuelle (2009), An adjoint sensitivity analysis of the southern California current circulation and ecosystem, J. Phys. Oceanogr., 39(3), 702-720.

Nof, D. (2005), The momentum imbalance paradox revisited, J. Phys. Oceanogr., 35(10), 1928-1939.

Ochoa, J., J. Sheinbaum, A. Badan, J. Candela, and D. Wilson (2001), Geostrophy via potential vorticity inversion in the Yucatan Channel, J. Mar. Res., 59, 725-747.

Ochoa, J., A. Badan, J. Sheinbaum, and J. Candela (2003), Canek: Measuring transport in the Yucatan Channel, in Nonlinear Processes in Geophysical Fluid Dynamics, pp. 275-286, Kluwer Acad., The Netherlands.

Oey, L. (2004), Vorticity flux through the Yucatan Channel and Loop Current variability in the Gulf of Mexico, J. Geophys. Res., 109, C10004, doi: 10.1029/2004JC002400.

Oey, L., H. Lee, and W. Schmitz, Jr (2003), Effects of winds and Caribbean eddies on the frequency of Loop Current eddy shedding: A numerical model study, J. Geophys. Res., 108(C10), 3324, doi:10.1029/2002JC 001698 .

Oey, L., T. Ezer, and H. Lee (2005), Loop Current, rings and related circulation in the Gulf of Mexico: A review of numerical models and future challenges, Geophys. Monogr. Am. Geophys. Union, 161, 3156.

Ohlmann, J., P. Niiler, C. Fox, and R. Leben (2001), Eddy energy and shelf interactions in the Gulf of Mexico, J. Geophys. Res., 106, 26052620

Pichevin, T., and D. Nof (1997), The momentum imbalance paradox, Tellus, Ser. A, 49(2), 298-319.

Schmitz, W. (2003), Notes on the Circulation in and Around the Gulf of Mexico, A Review of the Deep Water Circulation-Vol: 1, Harte Res. Inst. [Available at http://www.harteresearchinstitute.org/whats-news/ books/, accessed 10 June 2013.]
Schmitz, W. (2005), Cyclones and westward propagation in the shedding of anticyclonic rings from the loop current, Geophys. Monogr. Am. Geophys. Union, 161, 241-261.

Sheinbaum, J., J. Candela, A. Badan, and J. Ochoa (2002), Flow structure and transport in the Yucatan Channel, Geophys. Res. Lett., 29(3), 10-110-4, doi:10.1029/2001GL013990.

Stammer, D., C. Wunsch, R. Giering, C. Eckert, P. Heimbach, J. Marotzke, A. Adcroft, C. Hill, and J. Marshall (2002), Global ocean circulation during 1992-1997, estimated from ocean observations and a general circulation model, J. Geophys. Res., 107(C9), 3118, doi:10.1029/2001JC000888.

Sturges, W., and R. Leben (2000), Frequency of ring separations from the Loop Current in the Gulf of Mexico: A revised estimate, J. Phys. Oceanogr., 30(7), 1814-1819.

Veneziani, M., C. Edwards, and A. Moore (2009), A central California coastal ocean modeling study: 2. Adjoint sensitivities to local and remote forcing mechanisms, J. Geophys. Res., 114, C04020, doi:10.1029/ 2008JC004775.

Vukovich, F. M. (1988), Loop current boundary variations, J. Geophys. Res., 93(C12), 15,585-15,591.

Vukovich, F. M. (1995), An updated evaluation of the Loop Current's eddy-shedding frequency, J. Geophys. Res., 100 (C5), 8655-8659.

Vukovich, F. M. (2007), Climatology of ocean features in the Gulf of Mexico using satellite remote sensing data, J. Phys. Oceanogr., 37(3), 689-707.

Vukovich, F. M., and G. Maul (1985), Cyclonic eddies in the eastern Gulf of Mexico, J. Phys. Oceanogr., 15(1), 105-117.

Vukovich, F. M., B. Crissman, M. Bushnell, and W. King (1979), Some aspects of the oceanography of the Gulf of Mexico using satellite and in situ data, J. Geophys. Res., 84(C12), 7749-7768.

Zavala-Hidalgo, J., S. Morey, and J. O'Brien (2003), Cyclonic eddies northeast of the Campeche bank from altimetry data, J. Phys. Oceanogr., 33(3), 623-629

Zhang, W., J. Wilkin, J. Levin, and H. Arango (2009), An adjoint sensitivity study of buoyancy-and wind-driven circulation on the New Jersey inner shelf, J. Phys. Oceanogr., 39(7), 1652-1668.

Zhang, X., B. Cornuelle, and D. Roemmich (2011), Adjoint sensitivity of the niño-3 surface temperature to wind forcing, J. Clim., 24, 4480-4493. 